pdfpagemode $=$ UseNone 


\title{
Funding constraints and liquidity in two-tiered OTC markets*
}

\author{
Evangelos Benos ${ }^{\dagger} \quad$ Filip Žikeš ${ }^{\ddagger}$
}

\begin{abstract}
Using primary dealer transactional data from the government bond (gilt) market in the United Kingdom, we identify a new channel through which dealer funding constraints may impair liquidity in two-tiered OTC markets. The key finding is that funding constraints also inhibit dealers' ability to accommodate each others' trade requests in the inter-dealer segment, which limits their collective ability to manage inventories and share risk. As a result, funding constraints end up compromising liquidity above and beyond any direct effects caused by dealers' inability to accommodate client trade requests due to their individual balance sheet constraints.
\end{abstract}

Keywords: gilt market, liquidity, inter-dealer trading

JEL Classification: G10, G12, G14

*Earlier versions of this paper have appeared under the titles "Liquidity determinants in the U.K. gilt market" and "Liquidity Determinants in Two-Tiered OTC Markets." We are grateful to an anonymous referee of the Journal of Financial Markets for extremely useful feedback, to Ana Fernandes for helping us understand the ZEN data, and to James Knight and Elisabetta Vangelista for providing useful insights into the U.K. government bond market. We would also like to thank Francis Breedon, Vincent Fardeau, Mikael Mellegard, Angelo Ranaldo, Jonathan Relleen, Marti Subrahmanyam, Matthew Willison, an anonymous referee for the Staff Working Paper series, and seminar participants at the Bank of England, Cass Business School (City University), the Federal Reserve Board, Macquarie Asset Management, the ECB-SAFE-Waseda 2nd International Conference on Sovereign Bond Markets (March 2015), the 2016 International Risk Management Conference (IRMC), and the 2016 International Finance and Banking Society (IFABS) Conference for helpful comments and suggestions. The views expressed in this paper are those of the authors and not necessarily those of the Bank of England, the Financial Conduct Authority, the U.K. Debt Management Office, the Federal Reserve Board, or any other person associated with the Federal Reserve System. This research did not receive any specific grant from funding agencies in the public, commercial, or not-for-profit sectors.

${ }^{\dagger}$ Financial Market Infrastructure Directorate, Bank of England, 20 Moorgate, London, EC2R 6DA, United Kingdom. Email: evangelos.benos@bankofengland.co.uk. Tel: +44 (0)20 76013658

${ }^{\ddagger}$ Federal Reserve Board, Division of Financial Stability, 20th Street and Constitution Avenue, NW, Washington, DC, 20551, United States. Email: filip.zikes@frb.gov. 


\section{Introduction}

Liquidity, or lack thereof, was at the heart of the 2007-09 financial crisis. Many large and important financial markets that were previously considered highly liquid exhibited an unprecedented deterioration in market liquidity and elevated price volatility, especially after the collapse of Lehman Brothers. Examples include markets where counterparty risk or uncertainty about valuations cannot account for the persistent drops in market liquidity, such as the foreign exchange market (Mancini et al., 2013) and the U.S. Treasury market (Engle et al., 2012; Hu et al., 2013). Dealer funding costs and balance sheet constraints (Gromb and Vayanos, 2002; Brunnermeier and Pedersen, 2009), along with slow-moving capital (Mitchel et al., 2007; Duffie, 2010), have been proposed as likely drivers of the market liquidity dynamics during the crisis, and these dynamics remain an active area of research.

In this paper, we provide evidence on a new channel through which funding constraints may impair liquidity in two-tiered over-the-counter (OTC) markets (i.e., markets that feature an inter-dealer and a dealer-to-client segment), which may help further explain the sudden and severe drop of liquidity experienced in a number of financial markets during the recent financial crisis. The key intuition is that dealer funding constraints also inhibit their ability to accommodate other dealers' trade requests, which leads to reduced activity in the inter-dealer segment. As a result, dealers become less able to manage their inventories and transfer risk among each other, which, in turn, further exacerbates their inability to accommodate client trade requests and contributes to the liquidity dry-up. In other words, dealer funding constraints affect liquidity, in two-tiered OTC markets, both directly and indirectly via the inter-dealer segment. 
Using data from the U.K. government bond (gilt) market from January 2008 to June 2011 (i.e., during the peak of the recent financial crisis and the beginning of the eurozone sovereign debt crisis), we first show that the functioning of the inter-dealer segment is an economically important determinant of market liquidity in two-tiered OTC markets, along with (and controlling for) direct dealer balance sheet constraint effects. We then show that the functioning of the inter-dealer segment is itself adversely impacted by dealer balance sheet constraints and funding costs. These findings combined illustrate the indirect effect of dealer constraints on liquidity, via the inter-dealer segment of the market.

Our data are ideally suited for this task as they are derived from one of the world's largest government bond markets and also span an eventful period, including the financial crisis of 2007-09, the first round of asset purchases by the Bank of England (commonly known as quantitative easing, or QE), and the onset of the eurozone sovereign debt crisis of 2011. We use transactional data that cover secondary-market activity for all conventional gilts outstanding at any point during our sample period. The unique feature of our data is that they contain all transactions involving the primary dealers in the gilt market, including the identity of the dealer, transaction price, volume, and buy/sell flag. This allows us to associate gilt liquidity with dealer activity both in the time series and the cross-section of gilts and dealers.

We first examine the liquidity conditions in the gilt market over the January 2008 to June 2011 period, focusing on both aggregate and gilt-specific liquidity. We measure aggregate gilt market liquidity using the yield curve Noise, a measure of mispricing along the yield curve, as proposed by Hu et al. (2013). We document that the U.K. yield curve Noise increased almost fivefold during 2008, with the sharpest increase occurring in the wake of the Lehman Brother's default between 
October and December of 2008, similar to the liquidity deterioration experienced in the U.S. Treasury market during this period. We also estimate gilt-specific liquidity using individual gilt quoted spreads, as well as a new measure of the effective spread that is motivated by Jankowitsch et al. (2011) but is not biased by the intra-day volatility of the efficient price. ${ }^{1}$ Using both of these gilt-specific liquidity metrics, we show that execution costs in the dealer-to-client segment of the gilt market almost doubled during the recent financial crisis and remained elevated for a prolonged period of time.

We next examine how liquidity is influenced by primary dealer activity. For this, we first test three hypotheses that are motivated by the theoretical literature. In particular, we conjecture that market liquidity is directly and adversely affected by: (1) dealer balance sheet constraints, (2) less inter-dealer trading, and (3) less dealer competition.

The first hypothesis is motivated by the relation between funding and market liquidity as formalized by Brunnermeier and Pedersen (2009). The intuition is that as dealers expand their balance sheets, in response to client order flow, they become increasingly constrained and their ability to warehouse additional risk is diminished, contributing to reduced liquidity.

The second hypothesis is also motivated by the microstructure literature (e.g., Ho and Stoll, 1983), which suggests that the inter-dealer segment is used by dealers to share risk in two-tiered OTC markets. ${ }^{2}$ Consider, for example, a dealer whose client wants to sell a large quantity of long-term gilts. In the presence of an active inter-dealer market, the dealer could accommodate the client's order knowing that

\footnotetext{
${ }^{1}$ Žikeš (2017) further develops and examines in depth the asymptotic properties of this estimator.

${ }^{2}$ See also Lyons (1995) and Reiss and Werner (1998) for empirical evidence in the FX and stock markets respectively.
} 
she can subsequently offload some - or all - of these gilts in the inter-dealer market to reduce her inventory risk. A less active inter-dealer market might instead force the dealer to offer to only buy the gilts at a deep discount as compensation for the increased inventory risk. Therefore, reduced inter-dealer activity would ceteris paribus imply that dealers end up with riskier inventories because they would be less able to share risk with each other. This, in turn, would lead to less liquidity.

The third hypothesis, on the impact of dealer competition on liquidity (e.g., as in Huang and Masulis, 1999), could also be relevant for our study because some dealers were more constrained than the rest, during our sample period, while others (such as Lehman Brothers) exited the market altogether. This may have changed market dynamics, rendering liquidity provision less competitive and thereby raising execution costs.

With this in mind, we test these three hypotheses, in time series and panel regressions, controlling for other well-known determinants of market liquidity such as gilt characteristics and market conditions. We find broad support in the data for the first two hypotheses and weaker support for the third. Dealer balance sheet constraints and a lower fraction of inter-dealer trading are associated with less liquidity both in aggregate and in the cross-section of gilts with both effects being also economically significant. For instance, a one standard deviation decrease in the fraction of inter-dealer trading leads to an increase in trading costs, as captured by the effective and quoted bid-ask spreads, of about $£ 460,000$ to $£ 1.4$ million daily for end-users. This suggests that the inter-dealer segment in two-tiered OTC markets plays a key role in facilitating dealer inventory management and risk sharing, as formalized by Ho and Stoll (1983).

Given the significant impact of inter-dealer trading on liquidity, we then examine what drives inter-dealer trading itself. Our forth hypothesis therefore is that 
balance sheet constraints and elevated funding costs inhibit dealers' ability to accommodate each others' trade requests. To test this hypothesis, we calculate the fraction of inter-dealer trading for each individual dealer and condition it on dealerspecific and aggregate market characteristics. We find that, indeed, when dealers' balance sheets are most constrained, dealers decrease their relative amount of interdealer trading. Furthermore, we find that dealers mainly decrease the anonymous trading that they do with each other (via inter-dealer brokers), while their relative amount of direct, non-anonymous, trading does not significantly change. Thus, consistent with evidence from other markets (e.g. Di Maggio et al., 2017), dealers appear to strive to maintain their trading relationships, even when their balance sheets are constrained, by accommodating non-anonymous trade requests from other dealers.

More generally, the impact of balance sheet constraints on inter-dealer trading, suggests that the former can indirectly affect market liquidity, in two-tiered OTC markets, by inhibiting inter-dealer trading. Our conclusion therefore is that the relation between liquidity and dealer balance sheet capacity constraints, in twotiered OTC markets, can be more complex than previously thought.

The rest of the paper is organized as follows. In Section 2, we discuss the related literature. In Section 3, we describe the structure and recent developments in the U.K. gilt market and in Section 4 we describe our data and present summary statistics. In Section 5, we define the various liquidity measures and show estimates of gilt market liquidity over our sample period. In Section 6, we present the main hypotheses and the results from the time-series and panel regressions and we also explore the determinants of inter-dealer trading. In Section 7, we conclude. The Appendix provides more details on the effective spread measure that we propose. 


\section{Related literature}

Our paper is most closely related to a number of studies that aim to understand OTC market dynamics and in particular the role of the inter-dealer segment in twotiered markets. The seminal paper is Ho and Stoll (1983), which formally shows how the inter-dealer market can allow dealers to share inventory risk. Viswanathan and Wang (2004) and Dunne et al. (2015) explore the role of adverse selection in two-tiered markets and show that asymmetric information between clients and dealers can lead to breakdown of the inter-dealer segment. On the empirical side, Lyons (1995) documents that an FX dealer systematically uses the inter-dealer segment to control her inventory, while Reiss and Werner (1998) show that dealers, active on the London Stock Exchange (LSE), trade with each other more when they have extreme and opposite inventory imbalances. Our paper contributes to this literature by linking inter-dealer activity with market liquidity and by showing that when dealers are constrained they are less able to accommodate each others' trades in the inter-dealer segment, thus leading to a deterioration of inter-dealer activity.

Next, our work is related to the literature on the relation between market liquidity and funding constraints. Gromb and Vayanos (2010) provide a survey of the theory, while Krishnamurthy (2010) discusses a range of empirical examples from the 2007-09 financial crisis. In the context of government bond markets, the most relevant paper is that by $\mathrm{Hu}$ et al. (2013), who propose to measure marketwide liquidity in the Treasury market by yield curve Noise, i.e., the deviations of bond yields from a smooth fitted curve. They show that in periods of abundant risk capital, arbitrage smooths out the yield curve, while in periods of funding illiquidity and heightened risk aversion, large deviations in the prices of similar 
bonds may persist, consistent with the predictions of Gromb and Vayanos (2002), Brunnermeier and Pedersen (2009), and Duffie (2010), among others. Musto et al. (2017) find that liquidity feedback loops amplified the price discounts in Treasury securities during the recent financial crisis. In particular, less-liquid securities tended to flow to investors with longer horizons, thereby increasing their illiquidity but also their appeal to these investors. Fleckenstein et al. (2014) study the large and persistent mispricing between nominal and inflation-linked Treasury securities and, consistent with theory, find that the basis narrows when arbitrage capital flows into the market. Finally, Fontaine and Garcia (2012) use Treasury coupon bearing bonds to extract the value of funding liquidity and find that this predicts lower risk premia for Treasury securities, as a sign of flight to quality, but higher premia for other forms of debt, including corporate bonds. ${ }^{3}$ More recently, Bicu et al. (2017) examine the impact of the leverage ratio requirement on the U.K. gilt market. They show that during the period when the U.K. leverage ratio policy was announced, gilt liquidity deteriorated conditional on such factors as funding costs and inventory risk. However, the evidence on whether the effect is causal is, according to the authors, inconclusive. Our paper contributes to this strand of the literature by showing that, in two-tiered OTC markets, funding constraints can affect the mispricing of the yield curve, as well as overall market liquidity, not only directly (as the above papers show) but also indirectly by inhibiting activity in the inter-dealer segment of the market.

Our paper is also related to a number of theoretical and empirical studies on the role of dealer competition in OTC markets. On the theoretical side, our paper

\footnotetext{
${ }^{3}$ There are also several related papers that study the pricing effects of liquidity for corporate bonds during the crisis. Examples include Bao et al. (2011), Choi and Shachar (2013) and Dick-Nielsen et al. (2012). These papers find that liquidity explained a large share of corporate bond yields during the financial crisis.
} 
is closest to Dutta and Madhavan (1997), who model tacit collusion among dealers, and Bondarenko (2001), who formalizes the relation between the bid-ask spread and the degree of dealer competition as captured by the number of active dealers. On the empirical side, the most relevant paper is the one by Huang and Masulis (1999), who document that bid-ask spreads in the foreign exchange market decrease as competition increases after controlling for volatility.

Finally, our paper is related to the literature on the microstructure and liquidity of sovereign bond markets, particularly during periods of significant market stress. As highlighted by Engle et al. (2012) and Pelizzon et al. (2016), although there are numerous papers covering the government bond market microstructure, there are only a few studies on the recent episodes of market turbulence, such as the recent financial crisis or the euro-zone crisis, along with the subsequent unconventional monetary policy interventions. The few exceptions include Engle et al. (2012), who propose a new dynamic order book model and study the joint dynamics of liquidity and volatility in the U.S. Treasury market between 2006 and 2010. They find that liquidity decreased dramatically during the financial crisis and that liquidity and volatility exhibit negative feedback. Pelizzon et al. (2016) study the microstructure of the Italian government bond market during the eurozone crisis of 2011-2012, and document a strong relation between sovereign risk and market liquidity, as well as a positive impact on market liquidity of the European Central Bank interventions. Finally, Fullwood and Massacci (2017) study the related gilt futures market and find that it is highly resilient. We add to this literature by examining the liquidity of a thus far less-explored major European government bond market (that of U.K. government gilts) during a period of severe stress. More importantly, we go a step further by linking the observed liquidity dry-ups with the underlying market structure characteristics. 


\section{Institutional framework and market structure}

Conventional gilts are nominal fixed-coupon bonds issued by Her Majesty's Treasury (HMT) on behalf of the U.K. government. Even though the gilts are listed on the LSE, the vast majority of trading takes place over the counter. This involves bilateral transactions between market participants either over the phone or via an electronic trading platform (not operated by the LSE). Central to the functioning of the gilt market are the so-called gilt-edged market makers (GEMMs). These are financial institutions that have been designated as primary dealers in the gilt market by the U.K. Debt Management Office (DMO), an executive agency of HMT responsible for managing the debt of the U.K. government.

The GEMMs are obliged to provide liquidity in the secondary gilt market by making "on demand and in all conditions, continuous and effective two-way prices." ${ }^{4}$. Practically, this means that GEMMs stand ready to make markets and respond to a request for quotes by their customers at all times during normal business hours. The spread between the bid and ask prices that the GEMMs are required to quote should be "reasonable," although the U.K. Debt Management Office (DMO) does not provide a strict definition of what a "reasonable" spread is, given that the spread varies depending on market conditions. Overall, the rationale is that by providing liquidity at all times, the GEMMs should ultimately help reduce the borrowing costs for the U.K. government. In practice, the GEMMs are the primary source of liquidity in the gilt market and are a party to the vast majority of gilt transactions.

\footnotetext{
${ }^{4}$ United Kingdom Debt Management Office (2013), page 5. This obligation covers trades between the GEMM and its customers only. The GEMM is not obliged to provide quotes to other recognized GEMMs, inter-dealer brokers, or agency brokers, although the GEMM is not prohibited from doing so. Additionally, this obligation does not cover rump gilts, which are bond issues considered too small to be liquid.
} 
In exchange for their market-making obligations, GEMMs enjoy a number of privileges, such as the exclusive right to participate in gilt primary auctions run by the DMO and a non-competitive allowance of $10 \%$ of the amount of debt issued in each auction. Additionally, GEMMs have a preferred counterparty status, which means that the DMO will only deal with GEMMs when operating in the secondary market. Although designated as such by the DMO, GEMMs are supervised and monitored by the U.K. Financial Conduct Authority (FCA) and are required to report all their secondary-market trades in gilts to the FCA.

Apart from the GEMMs, an important element of the gilt-market structure are the inter-dealer brokers (IDBs). These are firms that operate exclusively as intermediaries between GEMMs, allowing them to complete transactions anonymously. Should a GEMM wish to trade with another GEMM, a direct communication between the two parties would reveal the parties' intentions to trade, which might compromise dealers' ability to effectively manage inventory. This, may in turn adversely affect market liquidity. IDBs themselves are not allowed to take proprietary positions, and they deal on a matched principle basis. In addition to the IDBs, there are also agency brokers operating in the gilt market who may broker trades between dealers and end-investors.

The GEMMs play a key role in the primary market for gilts as well. The DMO typically sells gilts either via outright auctions in which only GEMMs can participate, or via syndications. In a syndication, the DMO selects a group of GEMMs to manage the sale of a gilt on its behalf. When issuing debt, the DMO may either issue a new gilt or "tap" an existing gilt, i.e., it may sell an additional amount of a previously issued gilt. This typically happens multiple times over a number of years.

In response to the recent financial crisis, the Bank of England (BoE) introduced 
a program of asset purchases financed by central bank reserves, commonly known as quantitative easing (QE). During the first round of QE from March 2009 to January 2010, which overlaps with our sample period, the BoE purchased $£ 200$ billion worth of gilts in the secondary market via reverse auctions. These purchases represented a significant fraction of issuance and seemed to have lowered gilt yields (Joyce and Tong, 2012). At the same time, new issuance of gilts by HMT continued at a relatively fast pace amid the recession following the financial crisis. Figure ?? shows the cumulative amount of debt issued by HMT, the cumulative amount of QE purchases, and the difference between the two, i.e., the free float. One can see that the free float remained relatively stable during the QE period, as $\mathrm{QE}$ purchases reduced stocks by almost as much as HMT increased them.

\section{Data and summary statistics}

The main source of our data is the ZEN database maintained by the U.K. Financial Conduct Authority (FCA). ${ }^{5}$ ZEN contains reports for all secondary-market trades in gilts where at least one party is an FCA-regulated entity. Given that all GEMMs are U.K. domiciled and hence FCA-regulated institutions, our data fully cover the trading activity of these institutions.

Each transaction report contains information on the transaction date and time, gilt International Identification Securities Number (ISIN), execution price, size of the transaction, buyer/seller flag, and an agency/principle capacity flag. The most important feature of the reports is that they contain the identity of the party submitting the report and frequently, but not always, the identity of their counter-

\footnotetext{
${ }^{5}$ The ZEN data are also used by Czech and Roberts-Sklar (2017) to study how investors in the U.K. corporate bond market react to changes in yields.
} 
party. ${ }^{6}$ However, because all FCA-regulated firms have to report their transactions, a trade between FCA-regulated firms would be reported separately by each firm and hence we can match these reports based on transaction characteristics. Thus, we can match all reports pertaining to (1) direct inter-dealer trades, (2) all legs of inter-dealer trades brokered by inter-dealer brokers, and (3) dealer-client trades involving FCA-regulated end investors. Dealer-client trades involving non-FCAregulated end investors would only be reported once, by the GEMM, and we would not always be able to identify the GEMM's counterparty.

We match our transactional data with publicly available information on total issuance, maturity, coupons, bond durations and end-of-day closing prices obtained from the DMO. ${ }^{7}$ To construct daily quoted spreads, we use end-of-day bid and ask quotes from Bloomberg. ${ }^{8}$

We use the BoE's data on QE auctions to adjust the total amount outstanding of each gilt by the BoE's purchases and construct the total privately held amount of each gilt (free float). We also use daily time series for a number of other variables: we obtain the five-year U.K. sovereign credit default swap (CDS) spread from Markit, the three-month sterling London Inter-Bank Offered Rate (LIBOR) from Datastream and daily values of the three-month sterling general collateral repo rate from the BoE.

Our sample covers the period from January 2008 to June 2011 and consists of

\footnotetext{
${ }^{6}$ We do not always see the counterparty identity because dealers sometimes use an internal code to designate their counterparties that cannot be used to directly infer the counterparties' identity.

${ }^{7}$ Gilt prices produced by the DMO during our sample period, were calculated by "...collating mid-market closing prices from each Gilt-edged Market Maker (GEMM) for those gilts in which it made markets (conventional gilts, index-linked gilts, or both, with the exception of rump gilts and STRIPS). The DMO published an averaged mid-price, together with an associated gross redemption yield, as the Gilt-edged Market Makers Association (GEMMA) reference price." For more information see: http://dmo.gov.uk/index.aspx?page=Gilts/Daily_Prices

${ }^{8}$ Bloomberg collects this information from dealers and reports their averages.
} 
883 business days. There were 43 different conventional gilts traded at some point during this period, including gilts issued both prior to the beginning of the sample period and during the sample period. The number of primary dealers over 2008 to 2011 varies as some firms lost their GEMM status (e.g., Lehman Brothers due to bankruptcy in 2008 and Commerzbank AG due to resignation in 2009) while new firms acquire it (e.g., Nomura in March 2009 and Toronto Dominion in April 2010). In total, there were 24 different GEMMs during the sample period.

Table ?? reports summary statistics for the gilts in our sample. For every six-month period, starting in June and December, we group the outstanding gilts into four residual-maturity buckets and calculate for each bucket the number of gilts outstanding, together with cross-sectional statistics for coupon, issuance, and percentage of issuance held by the BoE through its QE program. The table shows that the number of gilts outstanding, as well as the average issuance increased over time across all maturities. The average coupon decreased during the sample period, mainly for shorter maturity gilts, reflecting the cuts in the BoE rate (i.e., the BoE's main policy rate) and the fact that the DMO issues new gilts with market value close to par. The asset purchases by the BoE removed on average between $25 \%$ and $45 \%$ of the issuance depending on the residual maturity bucket and particular point in time, though the cross sectional maxima show that, at times, as much as $57 \%$ of the amount outstanding of a gilt was held by the Bank. Note that the cross sectional statistics vary over time not only because of the Bank's purchases, which were spread over 10 months, or because the gilts transition between maturity buckets, but also because the DMO tapped some of the outstanding gilts and thus increased the issuance of these gilts.

We next report summary statistics for market activity during our sample period. We measure all activity variables in par value terms throughout. Figure ?? 
shows that the monthly traded volume fluctuated between $£ 200$ billion and $£ 400$ billion. These numbers are large - they equal around 3 to 6 times the monthly traded volume of the shares listed on the LSE during the same period. The traded volume increases over time, partly reflecting the increasing stock of gilts in issue, as shown in Figure ??. However, the traded volume did not fully keep up with the rising issuance. As the bottom chart of Figure ?? shows, the monthly turnover actually decreased from 0.8 in January 2008 to 0.4 in June 2011. This implies that while in January 2008 the entire stock of gilts outstanding changed hands at a rate of around 10 times per year, in June 2011 it was only around 5 times per year. Similar drops in turnover were also observed in the U.S. Treasury market during this period. ${ }^{9}$

Table ?? shows summary statistics of market activity in the cross section of gilts. We group gilts into the four residual maturity buckets used in Table ?? and report, separately for each half-year and bucket, statistics for the monthly trading volume, the percentage of inter-dealer volume, the aggregate net secondary-market dealer volume, and the degree of dealer activity concentration as captured by the Herfindahl index. The statistics are calculated using all gilt-month observations within each half-year and bucket. The reported numbers suggest that there is considerable variation in the trading activity across the gilts in our sample. There are gilts whose monthly turnover equals a multiple of their amount outstanding, while others trade fairly thinly.

The proportion of inter-dealer trading, reported in the middle set of columns in Table ??, also varies significantly in the cross-section and over time, ranging from $0 \%$ to almost $75 \%$. Interestingly, the proportion of inter-dealer trading is substantially lower across all maturity buckets around the peak of the financial crisis

\footnotetext{
${ }^{9}$ SIFMA, www. sifma.org/research/statistics.aspx.
} 
between 2008-H1 and 2009-H2. In the next set of columns, we report statistics on net dealer volume, which is the total amount of gilts bought minus the total amount sold collectively by all dealers. The results show that dealers' net position changes are relatively small compared to the traded volumes and amounts outstanding. However, it is important to reiterate that the net dealer volume reported here only includes secondary-market trading activity.

Finally, in the last set of columns in Table ??, we report statistics on the degree of dealer activity concentration, as captured by the Herfindahl index. The index is calculated using the total volume traded by each dealer and by assigning a $50 \%$ share to each dealer in any inter-dealer trade. The reported averages suggest that dealer activity is generally moderately concentrated, with the shortest and longest maturities being slightly more concentrated than the rest. The reported maxima, however, also suggest that during the peak of the financial crisis, especially in 2009-H1, there were months and gilts on which trading was more concentrated, with the Herfindahl index reaching levels above 0.5.

\section{Gilt market liquidity}

We start our analysis by measuring liquidity in the gilt market during our sample period. We use different liquidity metrics exploiting both end-of-day quote information, as well as our unique transactional data. Specifically, we construct three liquidity measures: one describing aggregate liquidity and two calculated on a gilt-specific basis. 


\subsection{Aggregate liquidity}

Following $\mathrm{Hu}$ et al. (2013), we use the yield curve Noise to measure aggregate liquidity. The idea underlying the Noise measure is that in normal times, when arbitrage capital is abundant, arbitrage forces will smooth out the yield curve and keep pricing errors (Noise) small. When funding conditions tighten and risk aversion rises, however, the ability and willingness of market participants to keep bond prices aligned declines, and consequently the yield curve Noise increases. The existence of arbitrage opportunities due to funding illiquidity is not the only source of variation in the Noise measure. Widening bid-ask spreads can also contribute to the widening of the Noise measure even if the law of one price holds when accounting for transactions costs. The Noise measure therefore captures funding and market liquidity in a bond market and serves as a good metric for gauging overall liquidity conditions.

Constructing the Noise measure requires a smooth model of the yield curve. Following Hu et al. (2013) and Malkhozov et al. (2014), we employ the well-known Svensson model (Svensson, 1994) for the instantaneous forward curve:

$$
f(m, \boldsymbol{b})=\beta_{0}+\beta_{1} \exp \left(\frac{-m}{\tau_{1}}\right)+\beta_{2} \frac{-m}{\tau_{1}} \exp \left(\frac{-m}{\tau_{1}}\right)+\beta_{3} \frac{-m}{\tau_{2}} \exp \left(\frac{-m}{\tau_{2}}\right),
$$

where $\boldsymbol{b}=\left(\beta_{0}, \beta_{1}, \beta_{2}, \beta_{3}, \tau_{1}, \tau_{2}\right)$ is the parameter vector and $m$ is the bond maturity. ${ }^{10}$ As in $\mathrm{Hu}$ et al. (2013), we use conventional gilts with residual maturity between 1 and 10 years to fit the Svensson model. However, we do not use sterling Treasury bills in the estimation because they are known to be illiquid. ${ }^{11}$ While

\footnotetext{
${ }^{10}$ For robustness, we also experimented with cubic splines with and without a smoothness penalty (Fisher et al., 1995). The results reported later in this section are qualitatively similar across the different yield curve models and are available upon request.

${ }^{11} \mathrm{http}: / /$ www . bankofengland.co.uk/statistics/Pages/iadb/notesiadb/wholesale_ tbs_3months.aspx
} 
the BoE uses repo rates to anchor the short end of the yield curve (Anderson and Sleath, 2001), we avoid that so as not to plague our Noise measure with microstructure effects in the repo market. Letting $N_{t}$ denote the number of gilts with residual maturity between 1 and 10 years at time $t$, we estimate the parameters of the Svensson model by minimizing the duration-weighted sum of squared pricing errors:

$$
\boldsymbol{b}_{t}=\arg \min \sum_{i=1}^{N_{t}}\left[\left(P^{i}(\boldsymbol{b})-P_{t}^{i}\right) \times \frac{1}{D_{t}^{i}}\right]^{2},
$$

where $P_{t}^{i}$ denotes the end-of-day $t$ reference price of gilt $i$ as reported by the DMO, $P^{i}(\boldsymbol{b})$ is the model-implied price of gilt $i$ given parameters $\boldsymbol{b}$, and $D_{t}^{i}$ denotes the MacCauley duration of gilt $i$ on day $t$. Given the fitted yield curve, the Noise measure is defined as:

$$
\text { Noise }_{t}=\sqrt{\frac{1}{N_{t}} \sum_{i=1}^{N_{t}}\left[y_{t}^{i}-y^{i}\left(\boldsymbol{b}_{t}\right)\right]^{2}}
$$

where $y_{t}^{i}$ is the reference yield of gilt $i$ on day $t$ and $y^{i}\left(\boldsymbol{b}_{t}\right)$ is the model-implied yield of gilt $i$ obtained from the zero-coupon yield curve corresponding to the instantaneous forward curve $f\left(m, \boldsymbol{b}_{t}\right)$.

Figure ?? shows the evolution of the Noise measure during our sample period. For comparison, we also plot the LIBOR-repo spread, and the U.K. CDS spread. Similarly to the Noise measure derived from the U.S. Treasury market by $\mathrm{Hu}$ et al. (2013), we see that the U.K. Noise measure tends to be elevated during periods of market turbulence, such as the demise of Bear Stearns in March 2008, the aftermath of Lehman Brothers' default in September 2008, and the eurozone sovereign debt crisis of 2011-2012. Additionally, we observe that although the Noise started dropping significantly during the first quarter of 2009, the downward 
trend was temporarily interrupted during the first few months of the QE purchases by the BoE, which were initiated in March 2009.

More importantly, Figure ?? reveals a high degree of co-movement between the Noise measure, the LIBOR spread and the U.K. five-year CDS spread. Although not perfectly synchronized, all three variables increase substantially during the financial crisis from the fall of 2008 until the end of 2009. Given that the three variables are, respectively, a measure of liquidity, a proxy for the cost of funding, and a proxy for gilt inventory risk, this degree of co-movement is consistent with the link between market and funding liquidity: dealers' funding constraints, in combination with increased inventory risk, reduce dealers' ability to either engage in or facilitate arbitrage trades.

\subsection{Gilt-specific liquidity}

To measure individual gilt liquidity, we use two different metrics. The first is the quoted bid-ask spread normalized by the mid-quote. Thus, for gilt $j$ and day $t$, our quoted proportional bid-ask spread metric is:

$$
B A_{j t}=\frac{A s k_{j t}-B i d_{j t}}{M i d_{j t}}
$$

where $M i d_{j t}=\frac{A s k_{j t}+B i d_{j t}}{2}$.

The second liquidity metric utilizes the transactional data from the dealer-toclient (DtC) segment of the market and measures the proportional effective spread. As our transactions data do not contain reliable time stamps, we cannot construct intraday returns and measure the effective spread by using the first-order serial covariance (Roll, 1984), as is common in the literature. Instead, inspired by the dispersion metric developed by Jankowitsch et al. (2011), we base our measure on 
the average distance between the transaction price and the end-of-day midquote, which does not require knowledge of the time stamps:

$$
\hat{d}_{j t}=\sqrt{\frac{1}{n_{j t}} \sum_{i=1}^{n_{j t}}\left(p_{i j, t}-m_{j t}\right)^{2}},
$$

where $p_{i j, t}$ is the logarithmic price associated with DtC transaction $i$ in gilt $j$ on day $t, m_{j t}$ is the logarithmic end-of-day midquote, and $n_{j t}$ is the number of transactions in gilt $j$ on day $t$. However, this metric suffers from an important drawback: centering each transaction price by the end-of-day midquote, rather than the midquote prevailing at the time of the transaction, introduces an upward bias due to the intraday volatility of the mid-quote. To obtain an accurate measure of the effective spread, it is therefore necessary to remove the contribution of the intraday volatility to the dispersion metric $\hat{d}_{j t}$. Assuming [as in Roll (1984)] that the logarithmic intraday midquote follows a random walk and that market orders arrive independently over time, this estimator removes the contribution of the intraday volatility to the dispersion metric $\hat{d}_{j t}$. The proportional effective spread can then be approximated by: ${ }^{12}$

$$
E S_{j t}=\sqrt{\max \left\{2\left(3 \tilde{d}_{j t}^{2}-\hat{d}_{j t}^{2}\right), 0\right\}}
$$

where $\tilde{d}_{j t}=\sqrt{\frac{1}{n_{j t}-1} \sum_{i=1}^{n_{j t}}\left(p_{i j, t}-\bar{p}_{j t}\right)^{2}}$ and $\bar{p}_{j t}=\frac{1}{n_{j t}} \sum_{i=1}^{n_{j t}} p_{i, j, t}$. The idea underlying this estimator is that $\hat{d}_{j t}$ and $\tilde{d}_{j t}$ both depend on the effective spread and intraday volatility in expectation, but the latter metric is less sensitive to intraday volatility than the former. This gives us two equations with two unknowns and solving these equations for the effective spread in the Roll (1984) model leads to equation

\footnotetext{
${ }^{12}$ In the Appendix, we summarize the derivation of the estimator.
} 
(??). The censoring of the statistic at zero ensures that the estimator remains nonnegative. This approach is similar in spirit to the metric by Corwin and Schultz (2012), who use daily high and low prices to disentangle the contribution of the bid-ask bounce from the variation due to the mid-quote process, although we use all transaction prices rather than just the daily high and low prices.

To reduce the noise associated with the daily liquidity metrics, we construct calendar-month metrics by averaging the daily observations within each calendar month. We plot these two metrics over our sample period in Figure ??. Both metrics are clearly elevated during the financial crisis, although the effective spread starts from a higher level and drops sooner, by the end of 2009. Both plots suggest that the cost of trading in the gilt market almost doubled during the financial crisis.

\section{Liquidity determinants}

Our main goal is to examine how liquidity is related to dealer balance sheet constraints, funding costs, and inter-dealer activity. In doing so, we also examine (and control for) other potential determinants of liquidity that have been identified in the literature. Below we list and discuss the main hypotheses of interest.

\section{H1. Dealer balance sheet constraints have a negative direct impact on gilt-market liquidity.}

Our first hypothesis is that dealer balance sheet constraints translate into lower liquidity provision. Balance sheet constraints, which may result from elevated funding costs and/or directional client order flow, restrict dealers' ability to accommodate additional trade requests that would require them to further expand 
their balance sheet. As a result, when faced with such constraints, dealers quote wider spreads. This intuition is formalized in Gromb and Vayanos (2002) and Brunnermeier and Pedersen (2009).

H2. Less inter-dealer trading has a negative impact on gilt-market liquidity.

Our second hypothesis is that reduced activity in the inter-dealer segment of the market has a negative effect on liquidity. This can happen if dealers use the interdealer segment to transfer risk and manage their inventories, as in Ho and Stoll (1983). Knowing that she cannot easily offload a client's position in the inter-dealer market, a dealer may charge a wider spread to accommodate clients' requests.

\section{H3. Less dealer competition has a negative impact on gilt-market liquidity.}

A number of papers, such as Dutta and Madhavan (1997) and Bondarenko (2001), have shown that competition among dealers affects liquidity. In an OTC market, such as the one for gilts, there is a limited number of dealers whose ability to warehouse risk varies over time and in the cross-section. Thus, it is plausible that liquidity provision can become at times be concentrated to only a few dealers who may choose to exercise market power. Our third hypothesis therefore is that reduced competition will have a detrimental effect on liquidity.

\section{H4. Dealer balance sheet constraints lead to reduced inter-dealer activity.}

Our fourth hypothesis is that inter-dealer trading is itself a function of dealers' ability to warehouse risk. Given the potential impact of inter-dealer trading on liquidity, this hypothesis is crucial for establishing that dealer balance sheet constraints can indirectly affect market liquidity by limiting dealers' ability to accommodate each others' trades, thereby making them less able to manage their inventories and transfer risk. 
In the rest of this section we test these hypotheses by means of time-series and panel regressions.

\subsection{Liquidity time-series regressions}

We first estimate a time-series specification of the aggregate liquidity Noise measure. We use, as regressors, variables that capture the various aspects of dealer characteristics and dealer activity related to our hypotheses. We also use control variables that capture market conditions and gilt characteristics. Our time-series specification is:

$\Delta$ Noise $_{t}=\alpha+\sum_{i=0}^{1}\left(\beta_{i}\right.$ Netdealervlm $_{t-i}+\gamma_{i} \Delta$ Interdealer $_{t-i}+\delta_{i} \Delta$ Her findahl $\left._{t-i}\right)$

$$
+\boldsymbol{\eta}^{\prime} \Delta \text { marketvars }_{t-1}+\boldsymbol{\theta}^{\prime} \Delta \operatorname{giltvars}_{t}+\epsilon_{t}
$$

where Netdealervlm is the aggregate net dealer volume, Interdealer is the fraction of inter-dealer trading to total dealer activity, and Herfindahl is the standard Herfindahl concentration index, which equals the sum of squared dealer market shares. The market share of a dealer is in turn defined as the proportion of trading volume of the dealer divided by the total trading volume by all dealers.

Aggregate net dealer volume is used as a proxy for changes in dealers' inventories and ultimately their balance sheet capacity to warehouse risk. The intuition here is that as dealers' inventories increase, dealers become less able to take on additional inventory and their intermediation capacity declines. ${ }^{13}$ Thus, in the

\footnotetext{
${ }^{13}$ It is worth noting that signed net volume is a reasonable proxy for inventory imbalances provided dealers hold positive inventories. Anecdotal evidence suggests that this is indeed the case in the gilt market, especially since the start of the BoE QE program in 2009.
} 
presence of such balance sheet constraints, we would expect a positive relation between net dealer volume and marketwide illiquidity (Noise).

The fraction of inter-dealer trading is used as a proxy for dealers' ability to share risk in the inter-dealer market. If inter-dealer trading facilitates risk sharing and inventory management, then we would expect a negative relation with the Noise measure. Herfindahl, is intended to capture the degree of competition in liquidity provision. If a more competitive market is also a more liquid one, then we would expect a positive coefficient.

In terms of other controls, marketvars is a vector of market variables. We include the LIBOR-repo spread as a measure of dealers' and other market participants' funding costs and the U.K. CDS spread as a measure of inventory risk. The market variables are lagged so as to ensure that they are predetermined with respect to Noise. giltvars is a vector of aggregate gilt-market characteristics. To proxy for the easiness with which gilts can be obtained to establish short positions outside the repo market, we include the total amount of gilts available through securities lending. ${ }^{14}$ We also include the aggregate cumulative value of gilt purchases by the BoE, through quantitative easing, and the amount of gilts outstanding net of QE purchases (free float). We include these variables to control for supply and demand shocks that might correlate with the aggregate liquidity measure.

All non-stationary variables are differenced so as to avoid spuriousness and all regressions are estimated using monthly data to reduce the contribution of highfrequency noise. Thus, our time-series specification is rather conservative as the differencing may result in information loss and the monthly frequency reduces the number of observations. Additionally, the activity variables enter the specification both contemporaneously and in lags so as to capture any effects that may last

\footnotetext{
${ }^{14}$ We obtained these data from Markit.
} 
longer than a month.

The estimation results are reported in Table ??. For each activity variable, we also test whether the sum of contemporaneous and lagged variable coefficients is significantly different from zero and report the associated p-values. Aggregate net dealer volume is positively and strongly correlated with the Noise measure across specifications. This would be expected if dealers become more constrained when their inventory increases, rendering them less able to respond to liquidity demands. Inter-dealer trading is negatively associated with Noise, albeit the effect is only significant when both contemporaneous and lagged variables are jointly tested. This suggests that less inter-dealer trading is associated with less liquidity (i.e., more Noise), which is consistent with the intuition in Ho and Stoll (1983) that inter-dealer trading facilitates risk sharing and inventory control. The Herfindahl index of dealer concentration, on the other hand, appears to be uncorrelated with Noise.

In terms of the market variables, we find that the LIBOR-repo spread is positively related to Noise and the effect is statistically significant in all specifications. The LIBOR-repo spread alone explains almost $29 \%$ of the variation in the Noise (column (1)). This is consistent with the idea that the higher the cost of funding, the more difficult it is for dealers to fund their inventories and therefore the less able they are to supply liquidity. Finally, the gilt variables all have the expected signs, although the only consistently significant variable is the cumulative amount of QE purchases. Overall, the results from the time-series regressions suggest that dealer balance sheet constraints, along with reduced inter-dealer activity are significant determinants of gilt-market liquidity. 


\subsection{Liquidity panel regressions}

We next exploit the panel structure of our data (i.e., over time and across gilts) and conduct additional tests on the relation between gilt market liquidity on one hand and dealer funding constraints, inter-dealer trading, and dealer competition on the other. We employ the gilt-specific liquidity metrics and associate them with aggregate and gilt-specific dealer activity variables. Specifically, we estimate the following panel specification:

Illiqmetric $_{i t}=\alpha+\beta_{1}$ Netdealervlm $_{t-1}+\beta_{2}$ Interdealer $_{i t-1}+\beta_{3}$ Herfindahl $_{i t-1}$

$$
+\gamma^{\prime} \text { marketvars }_{t-1}+\boldsymbol{\delta}^{\prime} \text { giltvars }_{i t-1}+v_{i}+u_{i t}
$$

where $i$ denotes gilts (ISINs), $t$ denotes months, and Illiqmetric is any of the two gilt-specific (il)liquidity metrics defined in equations (??) and (??). These variables are monthly averages of their daily values. Netdealervlm is, as before, the aggregate net dealer volume across all ISINs and is a proxy for order flow imbalances faced by dealers. It is an aggregate rather than a gilt-specific variable because dealers' balance sheet constraints are a function of their overall gilt trading. In general, dealers can more easily accommodate clients' demand for liquidity if client order flow is balanced since they simply need to match buyers with sellers. On the contrary, when client order flow is imbalanced, they need to deploy their inventory to accommodate clients' demands. This, however, may be difficult if dealers are faced with balance sheet constraints. All in all, if balance sheet constraints matter, we would expect a positive and significant relation between our illiquidity metrics 
and dealers' lagged net aggregate volume. Interdealer and Herfindahl are also defined as previously, albeit at the gilt level.

marketvars is a vector of market variables. As before, these variables include the three-month LIBOR spread (difference between the three-month LIBOR and the three-month repo rate) and the CDS spread on five-year U.K. sovereign CDS contracts. giltvars is a vector of three gilt-specific characteristics: the duration, the cumulative amount of gilt purchased as part of the BoE QE program, and the total amount of gilts outstanding net of the QE purchases (free float). The duration is a proxy for inventory risk since longer duration bonds are more sensitive to interest rate fluctuations, while the cumulative QE and the free float capture demand and supply dynamics.

Table ?? provides the summary statistics for the variables used in the regression. These statistics highlight both the temporal and cross-sectional variability of our sample. The bid-ask and effective spreads range from $0.001 \%$ and $0.009 \%$ to $0.27 \%$ and $0.55 \%$, respectively, while aggregate net dealer volume ranges between $£-11.8$ billion and $£ 14$ billion. The fraction of inter-dealer trading ranges from $0 \%$ to $73 \%$ and dealer concentration also varies substantially, ranging from $6.6 \%$ to $79 \%$. Duration ranges from a few days (for newly issued gilts) to more than 20 years, while the cumulative amount of QE purchases ranges from $£ 0$ (for maturities not purchased by the BoE) to about $£ 13.6$ billion. Finally, the free float ranges from $£ 2.57$ billion to almost $£ 28$ billion. ${ }^{15}$

We estimate model (??), allowing for gilt-specific fixed effects. All independent variables enter the specification with a lag to ensure that they are pre-determined

\footnotetext{
${ }^{15}$ The activity statistics reported here are comparable to those reported in Table ?? with the only difference being that we now calculate statistics over the entire gilt-month universe instead of specific half-year periods and maturity buckets. Additionally, net dealer volume is now aggregated over all gilts.
} 
with respect to the dependent variables. Table ?? shows the results of these estimations. A higher lagged aggregate net trading volume on behalf of the dealers is invariably associated with increased execution costs, consistent with the notion that as dealers' balance sheets become more constrained, they are only able to supply liquidity at a higher cost. This is consistent with the relation between funding and market liquidity as formalized by Brunnermeier and Pedersen (2009). The coefficients on the share of inter-dealer trading (Interdealer) are negative and significant across specifications for both measures of illiquidity. This is consistent with the idea that dealers use the inter-dealer market to share and shift risk and to the extent that they are less able to do so, they will demand a premium in the form of higher spreads for the additional risk that they are forced to bear. The coefficients on dealer concentration (Herfindahl) are also positive (albeit only significant for the bid-ask spread specifications), suggesting that market power is also a determinant (albeit a weak one) of the cost of liquidity. The control variables also have the expected signs. The LIBOR spread and the CDS spread are positively and statistically significantly related to the illiquidity metrics. This suggests that dealer funding costs and inventory risk all matter for gilt-market liquidity. The importance of inventory risk is also evident in the positive coefficients on gilt duration. Finally, free float is mostly insignificant, whereas cumulative QE is mostly negatively associated with the illiquidity metrics. Overall, the results on net dealer volume and inter-dealer trading are consistent with the ones in the Noise specification (??) and confirm the role of balance sheet constraints and of the inter-dealer segment in explaining variations in gilt market liquidity.

It is useful to also assess the economic significance of these variables. The estimated coefficients in Table ?? suggest that a one standard deviation increase in net dealer volume is associated with an increase in effective/quoted spreads by 
between 0.10 and 0.22 standard deviations or between $0.008 \%$ and $0.012 \%$ of the prevailing mid-quote. Similarly, a one standard deviation decrease in inter-dealer trading is associated with an increase in effective spreads by between 0.07 and 0.20 standard deviations or between $0.004 \%$ and $0.013 \%$ of the prevailing mid-quote. While these effects may seem small, the average daily traded volume in the DtC segment of the gilt market is fairly large, at about $£ 10.5$ billion. This means that even small changes in spreads translate into large absolute changes in execution costs. For example, when the above changes in spreads are multiplied by the daily average traded volume of the DtC segment, the daily increase in execution costs ranges from $£ 820,000$ to $£ 1.3$ million for every one standard deviation increase in net dealer volume and between $£ 460,000$ and $£ 1.4$ million for every one-standard deviation increase in inter-dealer trading.

\subsection{Inter-dealer trading panel regressions}

Given that inter-dealer activity has explanatory power over liquidity, we next examine whether dealers' balance sheet constraints and funding costs have explanatory power on inter-dealer trading itself. We exploit the fact that we observe trader identities and calculate, for each dealer, the percentage of inter-dealer trading as a fraction of their total volume and associate this with dealer-specific and marketwide variables. Our empirical specification is a panel:

Interdealer $_{i t}=a+\beta N$ etVlmRatio $i t-1+\gamma$ Dealer_CD $S_{i t-1}+\delta L I B O R_{-}$Spread $_{t-1}+v_{i}+u_{i t}$

where $i$ denotes individual dealers and $t$ denotes months. The dependent variable, Interdealer, is the ratio of a dealer's volume traded with other dealers divided by the dealer's total trading volume. We construct three versions of this ratio: 
one using all inter-dealer trades, one using only brokered trades and one using only non-brokered trades. As mentioned in Section 3, inter-dealer brokers (IDBs) enable dealers to trade with each other anonymously, which means that dealers face a different set of incentives when trading via an IDB versus trading directly with each other. For example, a dealer who is balance-sheet constrained and may not wish to expand his inventory, may still accommodate a direct (i.e., non-anonymous) sell request by another dealer so as to maintain a good trading relationship with them. It is therefore of interest to examine whether balance sheet constraints affect brokered and non-brokered inter-dealer trading the same way. NetVlmRatio is the ratio of each dealer's net volume divided by the dealer's total volume. ${ }^{16}$ This captures the degree to which each dealer's balance sheet expands or contracts relative to his total traded volume. If dealers become more constrained when their balance sheet expands and therefore less able to accommodate other dealers' trade requests, then we would expect the coefficients on lagged NetVlmRatio to be negative. Alternatively, when dealers are most constrained, they could in principle seek to trade more in the inter-dealer market so as to alleviate these constraints. In this case, one would expect the coefficients on NetVlmRatio to be positive. ${ }^{17}$ Dealer_CDS is the dealer-specific five-year CDS spread and is used as an estimate of the credit risk (and therefore of the funding cost) of each individual dealer.

Table ?? provides summary statistics of the dealer-specific activity variables used in this specification. As one can see, inter-dealer trading accounts, on average, for about $62 \%$ any given dealer's volume. Of this, the largest fraction is brokered ( $47 \%$ of total volume) and the remaining is non-brokered (14\% of total volume).

\footnotetext{
${ }^{16}$ Given that the dependent variable is a ratio, we also specify this variable relative to total volume.

${ }^{17}$ Unfortunately we cannot identify the initiators in the inter-dealer trades, so as to be able to examine this in more detail.
} 
The results of the dealer panel regressions are shown in Panel A of Table ??. The coefficients of NetVlmRatio are negative and significant, suggesting that as dealers' balance sheets expand, their ability to accommodate other dealers' trade requests declines. The coefficients on the $L I B O R_{-}$Spread suggest a similar story: they are negative throughout indicating that the higher dealers' funding costs, the less able or willing they are to trade with other dealers. We repeat this estimation using brokered and non-brokered inter-dealer trades and report the results in Panels $\mathrm{B}$ and $\mathrm{C}$ respectively. The results suggest that it is mainly the brokered inter-dealer trading volume that is reduced when dealers become constrained, with the reduction in trading being both economically and statistically more significant than in non-brokered volumes. For instance, a higher LIBOR spread is strongly associated with less brokered trading but not significantly associated with nonbrokered inter-dealer trading. These results suggest that dealers try to maintain their trading relationships with other dealers and primarily reduce their anonymous trading when they become constrained. This finding is similar to the evidence in Di Maggio et al. (2017), who show that dealers in the U.S. corporate bond market continue to provide liquidity during periods of stress to those counterparties with whom they have strong trading relationships. This suggests that similar trading relationship dynamics are at play in the U.K. gilt market.

Overall, given the positive effect of inter-dealer trading on liquidity, documented earlier, the fact that dealer balance sheet constraints and funding costs inhibit inter-dealer trading suggests that the impact of these constraints on market liquidity may be amplified in the presence of a two-tiered market (with an inter-dealer segment), as it hampers dealers' ability to share risk with each other. 


\section{Conclusion}

Using proprietary transactional data from the U.K. gilt market, we examine in this paper the relation between dealer balance sheet constraints and market liquidity in two-tiered OTC markets. In particular, we empirically identify an indirect link between the two, that operates via the inter-dealer segment: as dealers become constrained, they are less able to accommodate each others' trade requests causing the inter-dealer market to slow down. This, in turn, inhibits dealers from sharing risk, which exacerbates illiquidity above and beyond any effects stemming from individual dealers' own balance sheet constraints.

Our findings highlight the inter-dependence of dealers' balance sheets with market liquidity. The effect we document is likely to be especially strong at times of market-wide stress when large numbers of dealers become funding-constrained at the same time, and as a result there is little spare aggregate balance sheet capacity among them to facilitate risk sharing. Our paper shows that this effect was at play in the U.K. gilt market during the peak of the recent financial crisis and the onset of the eurozone sovereign debt crisis, but we conjecture that it may also have contributed to the sudden and pronounced drop in liquidity experienced, at about the same time, in other two-tiered OTC markets as well, such as the Treasury and FX markets.

More generally, our results suggest that the relation between funding and market liquidity is dependent on the specific design and the institutional and organizational characteristics of a given market and that these characteristics can potentially amplify the effects on market liquidity previously identified in the literature. 


\section{A Appendix}

In this appendix, we derive the measure of effective spread introduced in Section 5.2. We assume that the day is divided into $n$ subintervals of equal length (in tick time) and that a transaction arrives at the beginning of each of these subintervals. We also assume that the associated logarithmic transactions prices, $p_{i}, i=1, \ldots, n$, are related to the logarithmic efficient price, $m_{i}$, by:

$$
p_{i}=m_{i}+\frac{s}{2} q_{i}, \quad i=1, \ldots, n,
$$

where $s$ is the proportional effective spread and $q_{i}$ is a binary variable indicating whether the $i$-th transaction is buyer-initiated $(+1)$ or seller-initiated $(-1)$. Since we cannot construct intraday returns, we cannot use the first-order autocovariance to estimate $s$ as is standard in the microstructure literature following Roll (1984). Nor can we use the various realized measures developed in the financial econometrics literature (Ait-Sahalia and Jacod, 2014, Ch. 7) to estimate $\sigma$ in the presence of microstructure noise (induced by $q$ ). We can nonetheless construct statistics that use all transactions prices but do not require the knowledge of time stamps.

In many OTC markets, the efficient price may be observable at some point during the trading day. Here we assume for simplicity that $m$ is observed at the end of the day, i.e., at the end of the last subinterval $n$, and denote it by $m_{n+1}$. To estimate the effective spread $s$, we follow Jankowitsch et al. (2011) and consider the statistic:

$$
\hat{d}^{2}=\sum_{i=1}^{n}\left(p_{i}-m_{n+1}\right)^{2} w_{i} .
$$

where $w_{i}, i=1, \ldots, n$ are weights satisfying $\sum_{i=1}^{n} w_{i}=1$. Jankowitsch et al. (2011) take $w_{i}=V_{i} / \sum_{i=1}^{n} V_{i}$, where $V_{i}$ is the volume associated with transaction $i$. It is 
implicitly assumed in this measure that the intraday volatility $\sigma$ of the efficient price is small, so that substituting $m_{n+1}$ for the unobserved $m_{i}$ entails only a minor distortion when estimating $s$. Here we do not make this assumption.

If the efficient price is not observable, we can consider instead of $\hat{d}^{2}$ the statistic:

$$
\tilde{d}^{2}=\frac{n}{n-1} \sum_{i=1}^{n}\left(p_{i}-\bar{p}\right)^{2} w_{i}
$$

where $\bar{p}=\sum_{i=1}^{n} p_{i} w_{i}$ is the mean transaction price. As will become clear shortly, this statistic has similar properties to the one in equation (??) and is superior for estimating $s$ even when $m_{n+1}$ is observable to the econometrician.

To get an idea about the properties of these estimators, we assume that the logarithmic efficient price $m$ follows random walk:

$$
m_{i+1}=m_{i}+\epsilon_{i+1}, \quad i=0, \ldots, n
$$

If we further assume that $q_{i}$ is uncorrelated with $m_{j}$ for all $i, j$ and take $w_{i}=1 / n$, it is straightforward to show that:

$$
\mathrm{E}\left(\hat{d}^{2}\right)=\frac{s^{2}}{4}+\frac{\sigma^{2}}{2}\left(\frac{n+1}{n}\right) .
$$

Similarly, for $\tilde{d}^{2}$ we get:

$$
\mathrm{E}\left(\tilde{d}^{2}\right)=\frac{s^{2}}{4}+\frac{\sigma^{2}}{6}\left(\frac{n+1}{n}\right)
$$

We see that both statistics are affected by the volatility of the intraday price and hence are biased estimators of the squared proportional spread $s^{2}$. Clearly, the bias of the latter statistic, $\tilde{d}^{2}$, is three times smaller than that of the original statistic 
proposed by Jankowitsch et al. (2011). Moreover, the difference between the two statistics can be used to construct an unbiased estimator of $s^{2}$ :

$$
\hat{s}^{2}=\frac{1}{2}\left(3 \tilde{d}^{2}-\hat{d}^{2}\right)
$$

By construction we have $\mathrm{E}\left(\hat{s}^{2}\right)=s^{2}$. It is easy to see that the estimator is not guaranteed to be nonnegative. To deal with the (occasional) negativity of the estimator, we follow Corwin and Schultz (2012) and censor the estimator at zero. The final estimator of the proportional effective spread is thus:

$$
E S=\sqrt{\max \left\{2\left(3 \tilde{d}^{2}-\hat{d}^{2}\right), 0\right\}}
$$

This estimator of the proportional spread is based on the key observation that, in expectation, $\hat{d}^{2}$ is larger than $\tilde{d}^{2}$ due to intraday volatility. To see if that is the case in our data, we report in Table ?? some descriptive statistics for these metrics. The statistics are pooled over gilts and are calculated for daily metrics as well as for calendar-month metrics, which are obtained by averaging the daily metrics within each calendar month. It is clear from the table that $\hat{d}^{2}$ is on average significantly higher than $\tilde{d}^{2}$ : the mean $\hat{d}^{2}$ is more than twice as high as the mean $\tilde{d}^{2}$. Moreover, $\hat{d}^{2}$ exceeds $\tilde{d}^{2}$ on more than $99.9 \%$ gilt-days and gilt-months. The uncensored estimator of the squared effective spread, $\hat{s}^{2}$, does get occasionally negative, in around $16 \%$ of the gilt-days in our sample, but as expected, averaging over calendar months significantly reduces the variability of the estimator and consequently the occurrence of negative estimates. We find negative $\hat{s}^{2}$ in only around $5 \%$ of the gilt-months in our sample.

In general, the lack of accurate time stamps is a common feature of many 
transactional data sets from OTC markets and hence our metric may be useful for measuring liquidity beyond the application in this paper ${ }^{18}$.

\footnotetext{
${ }^{18}$ Examples of recently studied OTC transactional data sets that lack accurate time stamps include the interest rate swap data (Chen et al., 2011) and the credit default swap data (Chen et al., 2012; and Benos et al, 2013).
} 


\section{Acknowledgements}

We are grateful to Ana Fernandes of the UK's Financial Conduct Authority for helping us understand the data and to James Knight and Elisabetta Vangelista of the U.K.'s Debt Management Office for providing useful insights into the UK government bond market. We would also like to thank Francis Breedon; Vincent Fardeau; Mikael Mellegard; Angelo Ranaldo; Jonathan Relleen; Marti Subrahmanyam; Matthew Willison; an anonymous referee for the Bank of England Staff Working Paper series; and seminar participants at the Bank of England, the Federal Reserve Board, Macquarie Asset Management, the ECB-SAFE-Waseda 2nd International Conference on Sovereign Bond Markets (March 2015), the 2016 International Risk Management Conference (IRMC) and the 2016 International Finance and Banking Society (IFABS) Conference for helpful comments and suggestions. All errors are ours. The views expressed in this paper are those of the authors and not necessarily those of the Bank of England, the Financial Conduct Authority, the UK Debt Management Office, the Federal Reserve Board, or any other person associated with the Federal Reserve System. This research did not receive any specific grant from funding agencies in the public, commercial, or not-for-profit sectors. 


\section{References}

Aït-Sahalia, Y. and J. Jacod, 2014, High-Frequency Financial Econometrics, Princeton University Press.

Anderson, N. and J. Sleath, 2001, New estimates of the U.K. real and nominal yield curves, Bank of England Working Paper no. 126.

Bao, J., Pan, J. and J. Wang, 2011, The Illiquidity of Corporate Bonds, Journal of Finance, 66(1), 911-946.

Benos, E., Wetherilt, A. and F. Žikeš, 2013, The structure and dynamics of the UK credit default swap market, Financial Stability Paper No. 25, Bank of England.

Bicu, A., Chen, L. and Elliott, D, 2017, The leverage ratio and liquidity in the gilt and repo markets, Bank of England Staff Working Paper No. 690.

Bondarenko, O., 2001, Competing market makers, liquidity provision and bid-ask spreads, Journal of Financial Markets 4, 269-308.

Brunnermeier, M. K. and L. H. Pedersen, 2009, Market Liquidity and Funding Liquidity, Review of Financial Studies, 22, 2201-2238.

Chen, K., Fleming, M., Jackson, J., Li, A. and A. Sarkar, 2011, An Analysis of CDS Transactions: Implications for Public Reporting, Staff Report No. 517, Federal Reserve Bank of New York.

Chen, K., Fleming, M., Jackson, J., Li, A. and A. Sarkar, 2012, An Analysis of OTC Interest Rate Derivatives Transactions: Implications for Public Reporting, Staff Report No. 557, Federal Reserve Bank of New York.

Choi, J. and O. Shachar, 2013, Did Liquidity Providers Become Liquidity Seekers?, Federal Reserve Bank of New York Staff Reports, 650.

Corwin, S. and P. Schultz, 2012, A Simple Way to Estimate Bid-Ask Spreads from Daily High and Low Prices, Journal of Finance, 67(2), 719-759.

Czech, R. and M. Roberts-Sklar, 2017, Investor behaviour and reaching for yield: evidence from the Sterling corporate bond market, Bank of England Staff Working Paper No. 685.

Di Maggio, M., Kermani, A. amd S. Song, 2017, The value of trading relations in turbulent times, Journal of Financial Economics, 124, 266-284. 
Dick-Nielsen J., Feldhütter, P. and D. Lando, 2012, Corporate bond liquidity before and after the onset of the subprime crisis, Journal of Financial Economics, 103, 471-492.

Duffie, D. 2010, Asset Price Dynamics With Slow-moving Capital, Journal of Finance, 65, 1238-1268.

Dunne, P., Moore M. and H. Hau, 2015, Dealer Intermediation Between Markets, Journal of the European Economic Association, Vol. 13(5), 770-804.

Dutta, P. and Madhavan, A., 1997, Competition and Collusion in Dealer Markets, Journal of Finance, Vol. 52, No. 1, 245-276.

Engle, R., Fleming, M., Ghysels, E. and G. Nguyen, 2012, Liquidity, Volatility, and Flights to Safety in the US Treasury Market: Evidence from a New Class of Dynamic Order Book Models, Staff Report No. 590, Federal Reserve Bank of New York.

Fisher, M., Nychka, D. and D. Zervos, 1995, Fitting the term structure of interest rates with smoothing splines, Finance and Economics Discussion Series, Board of Governors of the Federal Reserve System.

Fleckenstein, M., Longstaff, F.A. and H. Lustig, 2014, The TIPS-Treasury Bond Puzzle, Journal of Finance, 69(5), 2151-2197.

Fontaine, J.S. and R. Garcia, 2012, Bond Liquidity Premia, Review of Financial Studies, 25(4), 1207-1254.

Fullwood, J. and D. Massacci, 2017, Liquidity Resilience in the UK Gilt Futures Market: Evidence from the Order Book, working paper.

Gromb D. and Vayanos D., 2002, Equilibrium and Welfare in Markets with Constrained Arbitrageurs, Journal of Financial Economics 66, 361-407.

Gromb D. and Vayanos D., 2010, Limits of Arbitrage: The State of the Theory, NBER working paper No. 15821

Ho, T. and Stoll, H., 1983, The dynamics of dealer markets under competition, Journal of Finance, 38, 1053-1074.

Hu, G.X., Pan, J. and J. Wang, 2013, Noise as Information for Illiquidity, Journal of Finance, 68(6), 2341-2382.

Huang, R.D., Cai, J. and X. Wang, 2002, Information-Based Trading in the Treasury Note Interdealer Broker Market, Journal of Financial Intermediation, 11, 269-296. 
Huang, R.D. and Masulis, R.W., 1999, FX Spreads and Dealer Competition across the 24-Hour Trading Day, Review of Financial Studies, Vol. 12, No. 1, 61-93.

Jankowitsch, R., Nashikkar, A. and M.G. Subrahmanyam, 2011, Price Dispersion in OTC Markets: A New Measure of Liquidity, Journal of Banking and Finance, 35, 343-357.

Joyce, M. and M. Tong, 2012, QE and the gilt market: a disaggregated analysis, Economic Journal, 122(564), 348-384.

Krishnamurthy, A., 2010, How Debt Markets Have Malfunctioned in the Crisis, Journal of Economic Perspectives, 24(1), 3-28.

Lyons R, 1995, Tests of microstructural hypotheses in the foreign exchange market, Journal of Financial Economics 39, 321-351.

Li, H., Wang, J., Wu, C. and Y. He, 2009, Are Liquidity and Information Risks Priced in the Treasury Bond Market?, Journal of Finance, 64(1), 467-503.

Malkhozov, A., Mueller, P., Vedolin, A. and G. Venter, 2014, Funding Liquidity CAPM: International Evidence, Working paper, London School of Economics.

Mancini, L., Ranaldo, A. and J. Wrampelmeyer, 2013, Liquidity in the Foreign Exchange Market: Measurement, Commonality, and Risk Premiums, Journal of Finance, 68, 1805-1841.

Mitchel, M., Pedersen, L.H. and T. Pulvino, 2007, Slow moving capital, American Economic Review, 97(2), 215-220.

Musto, D., Nini, G. and K. Schwarz, 2017, Notes on Bonds: Illiquidity Feedback During the Financial Crisis, Working paper, University of Pennsylvania.

Pelizzon, L., Subrahmanyam, M.G., Tomio, D. and J. Uno, 2016, Sovereign Credit Risk, Liquidity, and ECB Intervention: Deus Ex Machina?, Journal of Financial Economics 122, 1, 86-115

Reiss C. and Werner I., 1998, Does Risk Sharing Motivate Interdealer Trading?, Journal of Finance 53, 1657-1703.

Roll, R., 1984, A Simple Implicit Measure of Effective Bid-Ask Spread in an Efficient Market, Journal of Finance, 39, 1127-1140.

Svensson, L., 1994, Estimating and Interpreting Forward Interest Rates: Sweden 1992-1994, Working paper, National Bureau of Economic Research.

United Kingdom Debt Management Office, 2013, GEMM Guidebook: A guide to the roles of the DMO and Primary Dealers in the UK government bond market, January 
Viswanathan, S. and J. Wang, 2004, Inter-Dealer Trading in Financial Markets, Journal of Business, Vol. 77, No. 4, 1-54.

Žikeš, F. (2017). Measuring Transaction Costs in the Absence of Timestamps. Finance and Economics Discussion Series 2017-045. Washington: Board of Governors of the Federal Reserve System. 


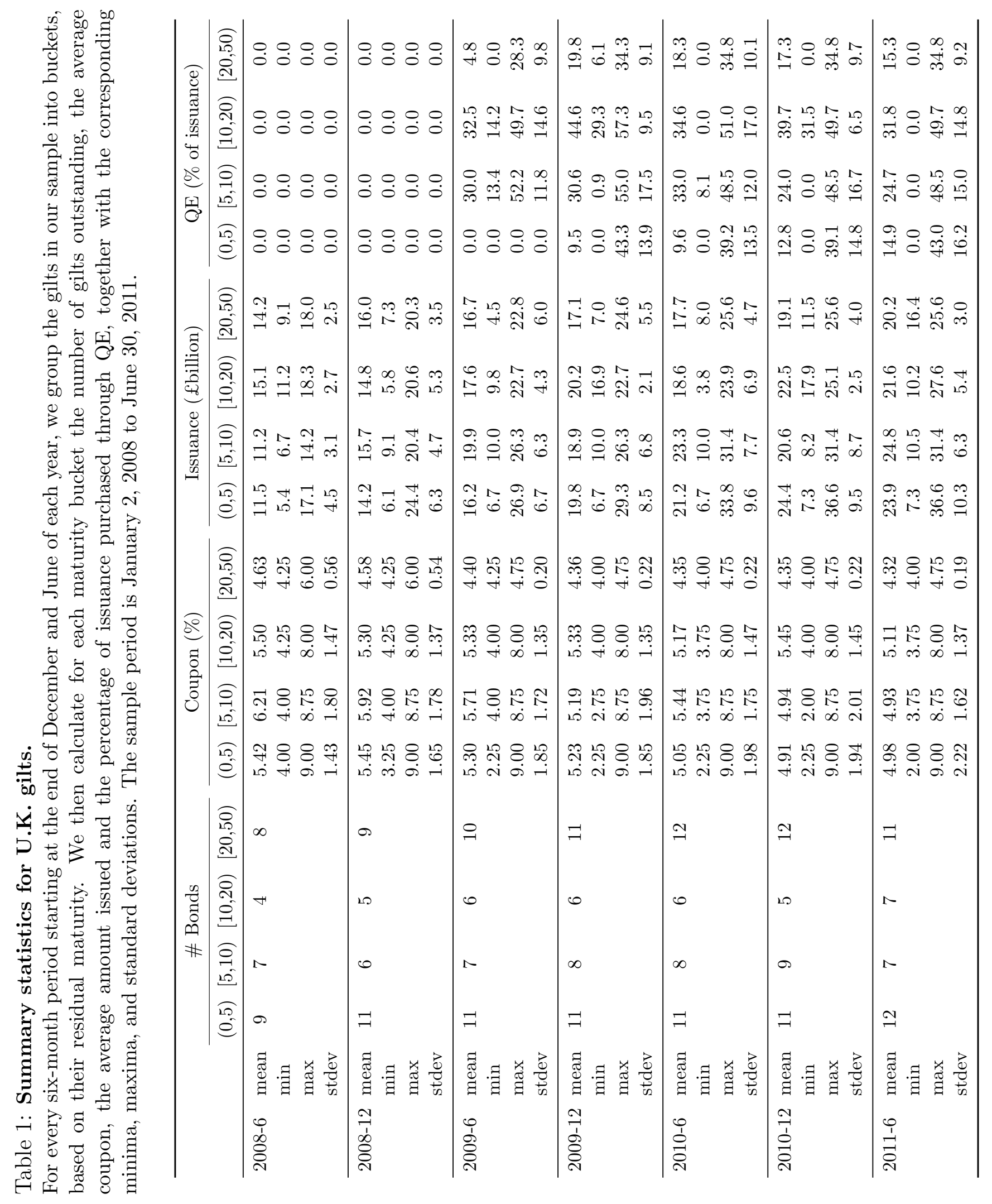




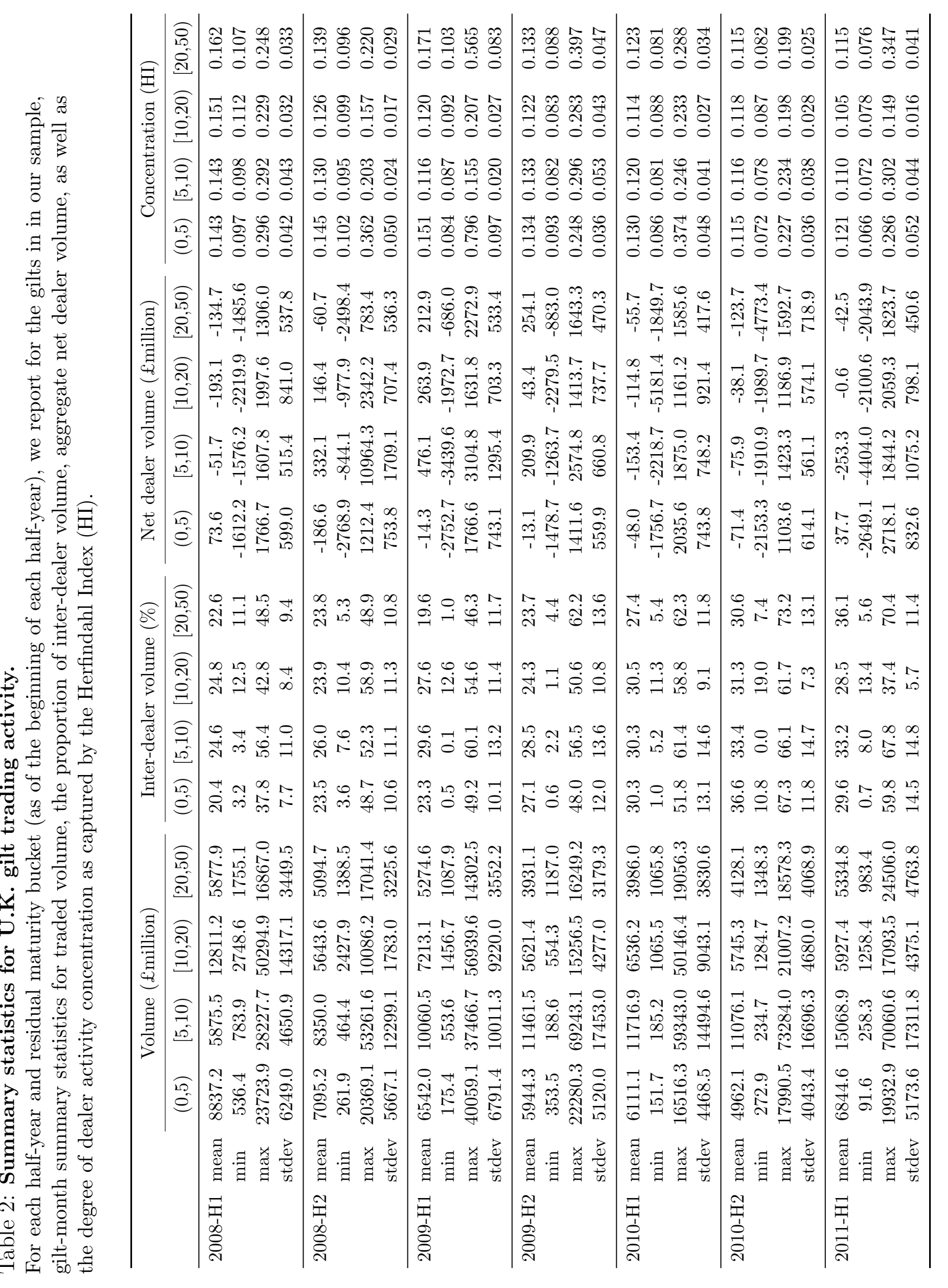




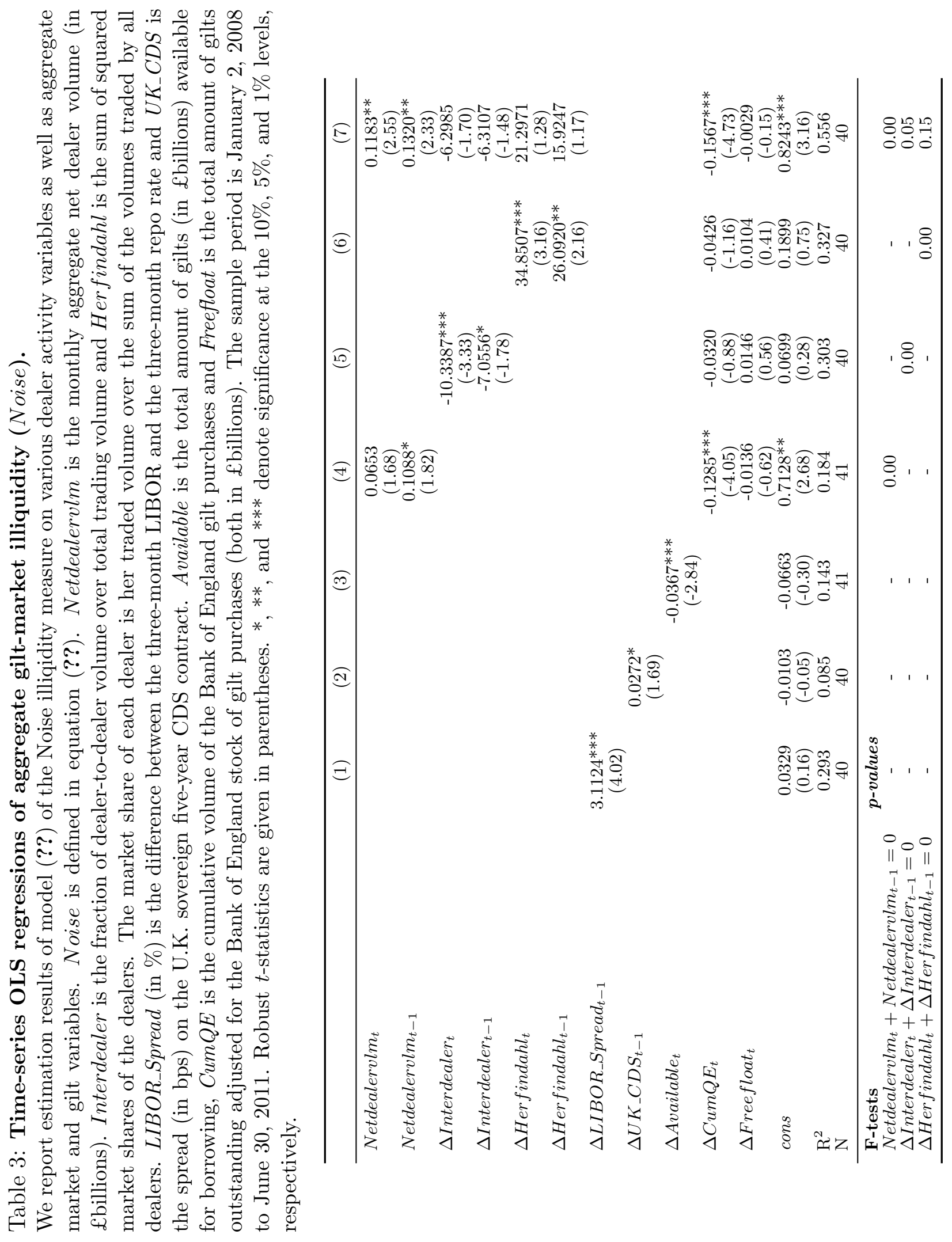




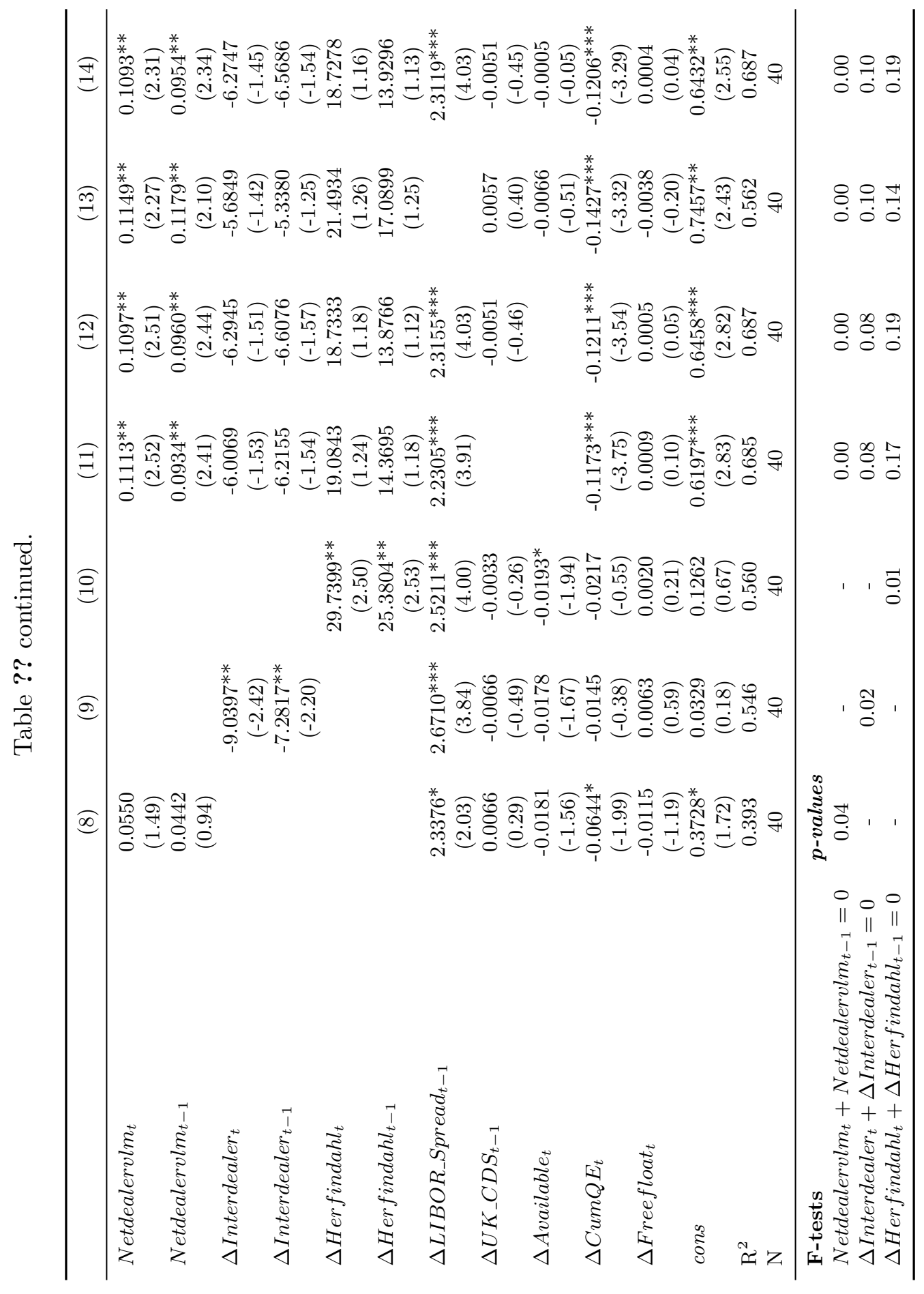


Table 4: Summary statistics of the variables used in specification (??).

The illiquidity metrics are defined in equations (??) and (??). Netdealervlm is the monthly aggregate (across gilts) net dealer volume (in £billions), Interdealer is the percent of inter-dealer trading in each gilt-month and Herfindahl is the gilt-month sum of squared market shares of the dealers. The market share of each dealer is the ratio of her traded volume over the sum of the volumes traded by all dealers in a given gilt-month. Libor_Spread is the difference between the three-month LIBOR and the three-month repo rate (in \%) and $U K_{-} C D S$ is the spread (in bps) on the U.K. sovereign five-year CDS contract. Duration is the bond duration in years; CumQE is the cumulative amount of QE purchases by the Bank of England in each bond (in £billions) and Freefloat is the total amount of debt outstanding for each bond (in £billions) adjusted for the Bank of England stock of bond purchases; The sample period is January 2, 2008 to June 30, 2011.

\begin{tabular}{lccccc}
\hline & $\mathrm{N}$ & Mean & Std. Dev. & Min & Max \\
\hline BA (bid-ask spread, \%) & 1402 & 0.077 & 0.048 & 0.001 & 0.274 \\
ES (effective spread, \%) & 1402 & 0.132 & 0.076 & 0.009 & 0.555 \\
Netdealervlm (£billions) & 42 & -0.591 & 5.567 & -11.757 & 14.000 \\
Interdealer & 1402 & 0.278 & 0.126 & 0.000 & 0.732 \\
Herfindahl & 1402 & 0.123 & 0.045 & 0.066 & 0.796 \\
LIBOR_Spread (\%) & 42 & 0.499 & 0.514 & 0.070 & 2.280 \\
UK_CDS (bps) & 42 & 63.939 & 30.166 & 8.620 & 145.300 \\
Duration (years) & 1402 & 8.675 & 6.084 & 0.020 & 21.930 \\
CumQE (£billions) & 1402 & 3.023 & 3.999 & 0.000 & 13.159 \\
Freefloat (£billions) & 1402 & 15.211 & 5.749 & 2.573 & 27.766 \\
\hline
\end{tabular}




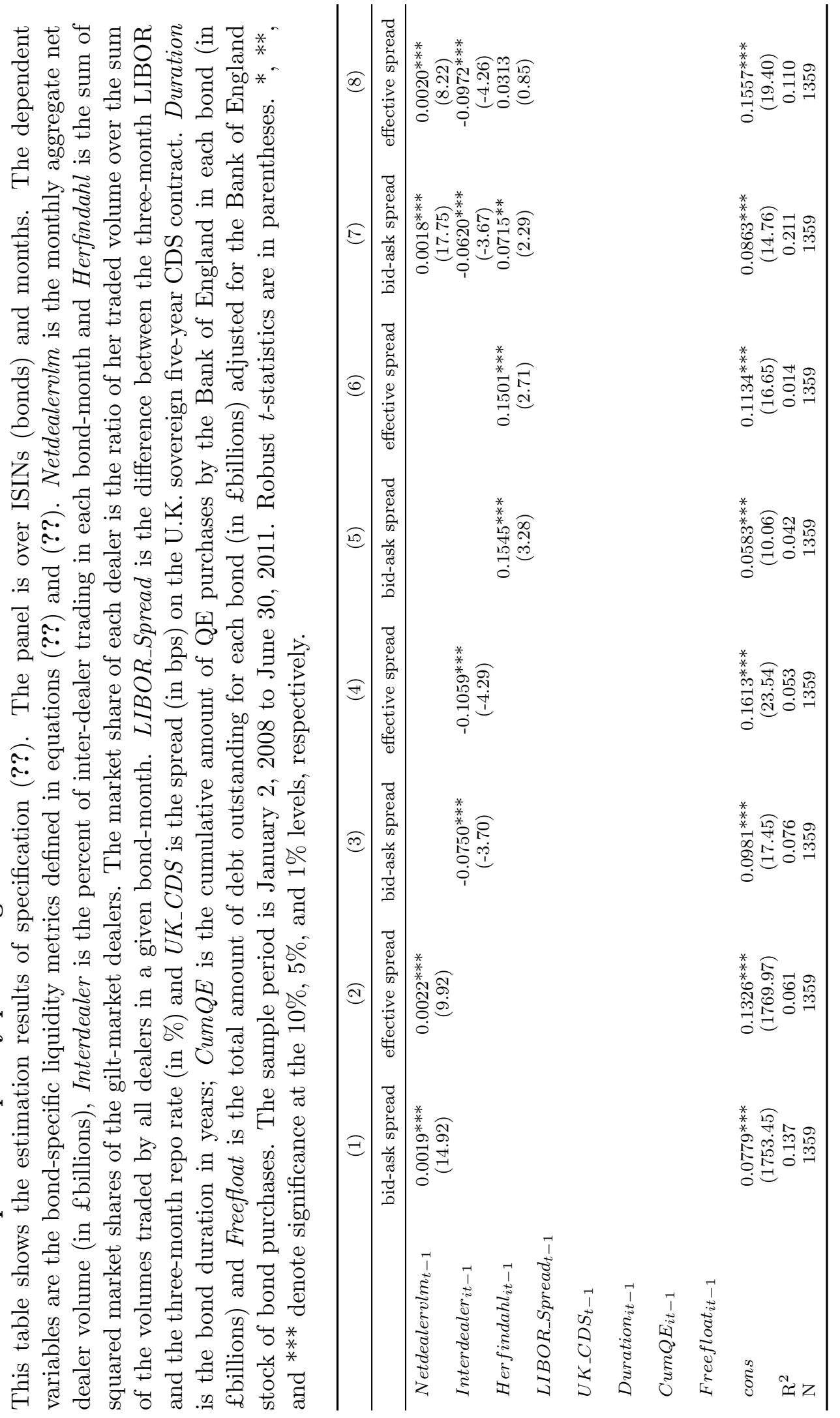




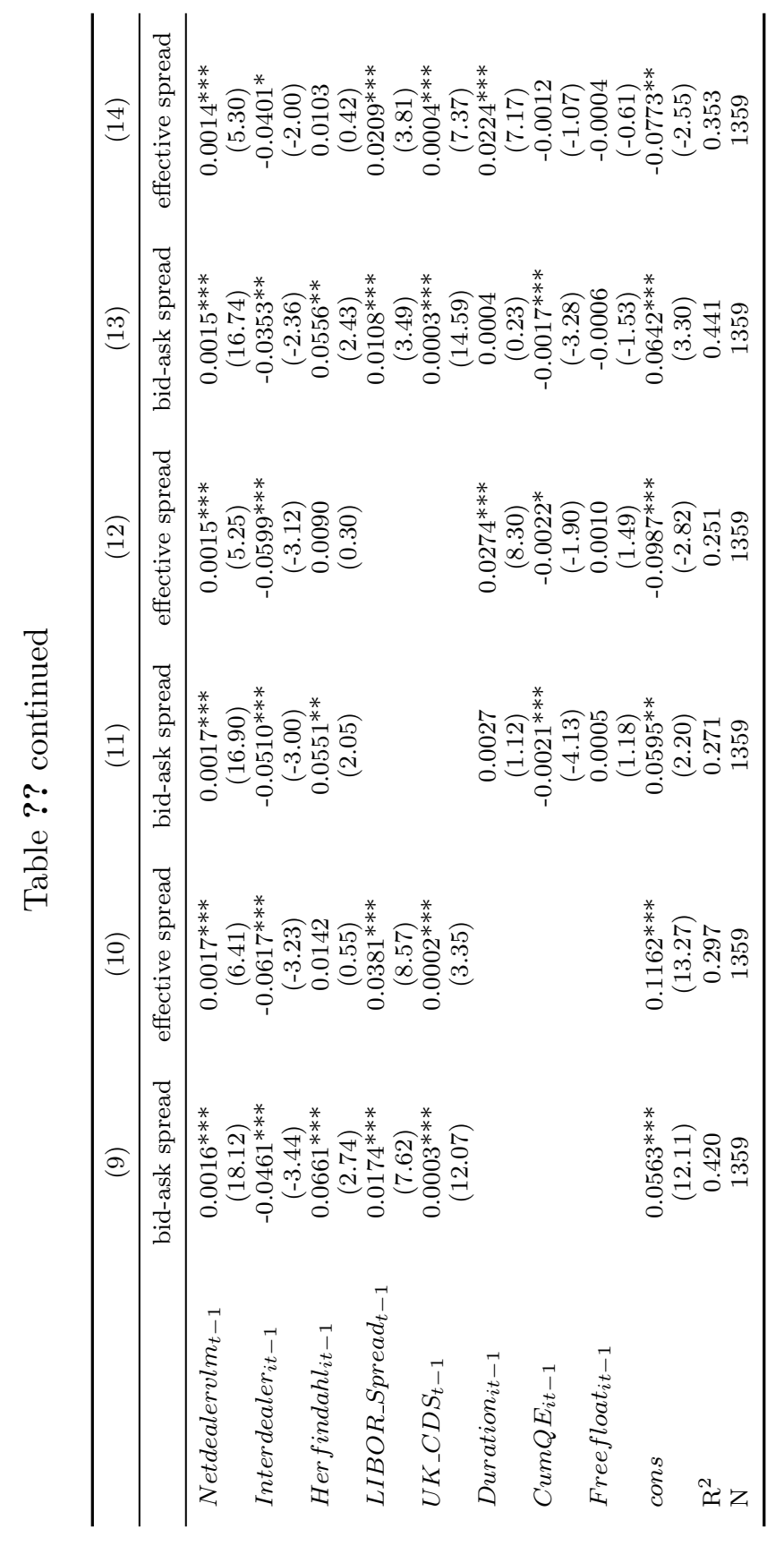


Table 6: Summary statistics of activity variables in specification (??).

Interdealer is the fraction of the individual dealer inter-dealer trading volume divided by the dealer's total traded volume, across all ISINs. NetVlmRatio is the dealer-specific ratio of the dealer's net volume divided by the dealer's total volume.

\begin{tabular}{lcccc}
\hline & Mean & Std. Dev. & Min & Max \\
\hline Interdealer (All trades) & 0.617 & 0.225 & 0 & 1 \\
Interdealer (Brokered trades) & 0.472 & 0.248 & 0 & 1 \\
Interdealer (Non-brokered trades) & 0.144 & 0.264 & 0 & 1 \\
NetVlmRatio & 0.002 & 0.235 & -1 & 1 \\
$\mathrm{~N}$ & 835 & & & \\
\hline
\end{tabular}




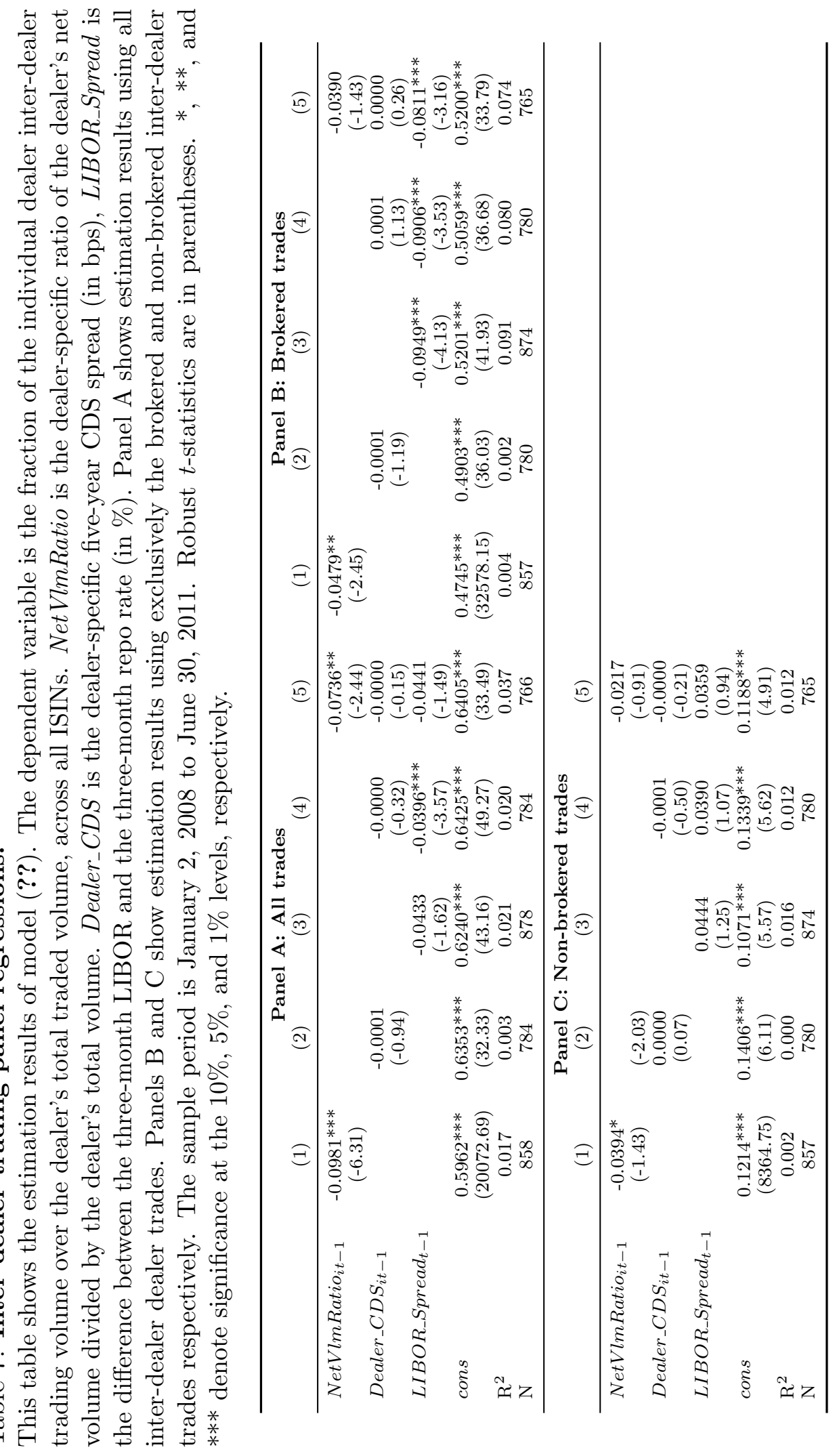


Table 8: Descriptive statistics for the dispersion metrics $\hat{d}^{2}$ and $\tilde{d}^{2}$.

We report results for daily metrics ("daily") and for calendar-month averages of daily metrics ("monthly"), pooled across gilts (i.e., for gilt-days or gilt-months). The bottom rows of the table report the percentage of gilt-days/gilt-months where the statistics $\left(\hat{d}^{2}-\tilde{d}^{2}\right)$ and $\left(3 \tilde{d}^{2}-\hat{d}^{2}\right)$ are negative.

\begin{tabular}{lcccccc}
\hline & \multicolumn{2}{c}{ daily } & & \multicolumn{2}{c}{ monthly } \\
\cline { 2 - 3 } \cline { 6 - 7 } & $\hat{d}^{2}$ & $\tilde{d}^{2}$ & & $\hat{d}^{2}$ & $\tilde{d}^{2}$ \\
\hline no. obs. & 24,110 & 24,110 & & 1,402 & 1,402 \\
mean & 0.985 & 0.441 & & 0.987 & 0.445 \\
std. dev. & 2.682 & 0.930 & & 1.282 & 0.532 \\
skewness & 15.28 & 7.649 & & 3.097 & 2.555 \\
kurtosis & 440.6 & 95.85 & & 16.91 & 11.97 \\
\hline negative $\left(\hat{d}^{2}-\tilde{d}^{2}\right)$ & $0.004 \%$ & & $0.071 \%$ \\
negative $\left(3 \tilde{d}^{2}-\hat{d}^{2}\right)$ & $16.28 \%$ & & & $4.921 \%$ \\
\hline
\end{tabular}


Figure 1: Issuance, free float and QE.

Total issuance, free float, and the stock of QE purchases in face-value terms (£billion) for the gilts in our sample. The sample period is January 2, 2008 to June 30, 2011.

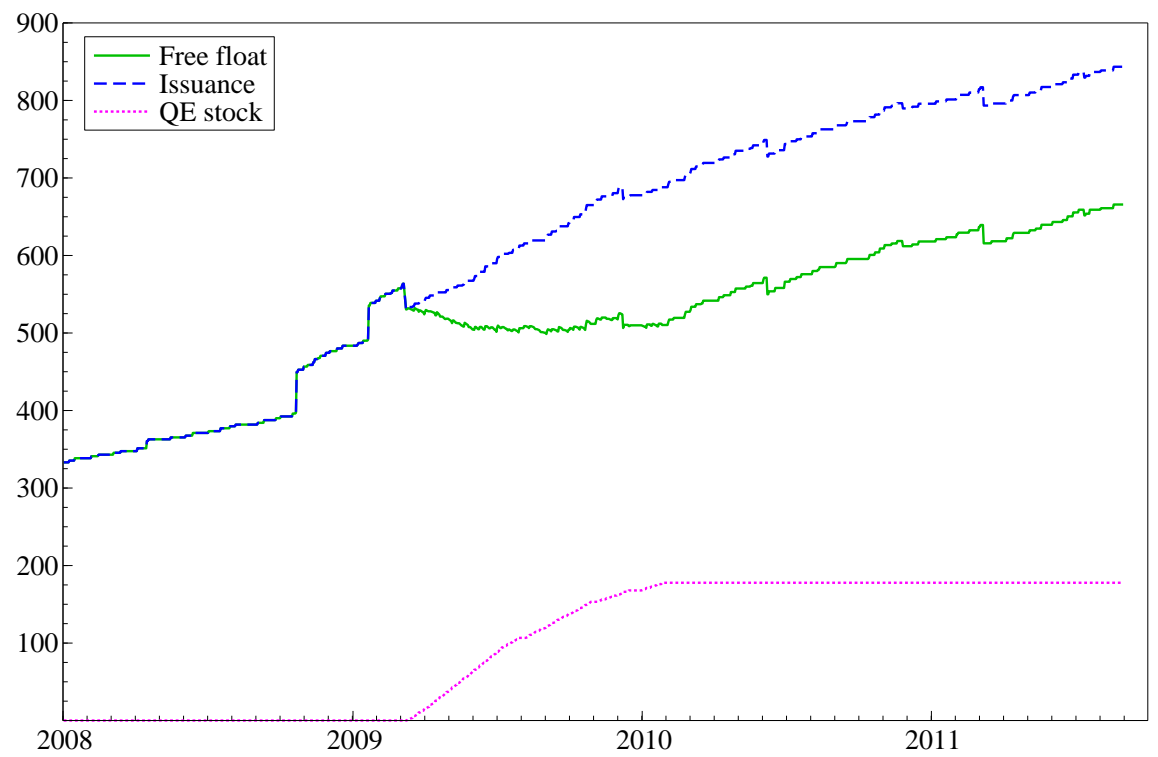


Figure 2: Trading activity.

The top chart shows the total monthly volume and monthly inter-dealer volumes (£billion, face value). The bottom chart shows the total monthly volume divided by the amount of gilts outstanding (monthly turnover). The sample period is January 2, 2008 to June 30, 2011.
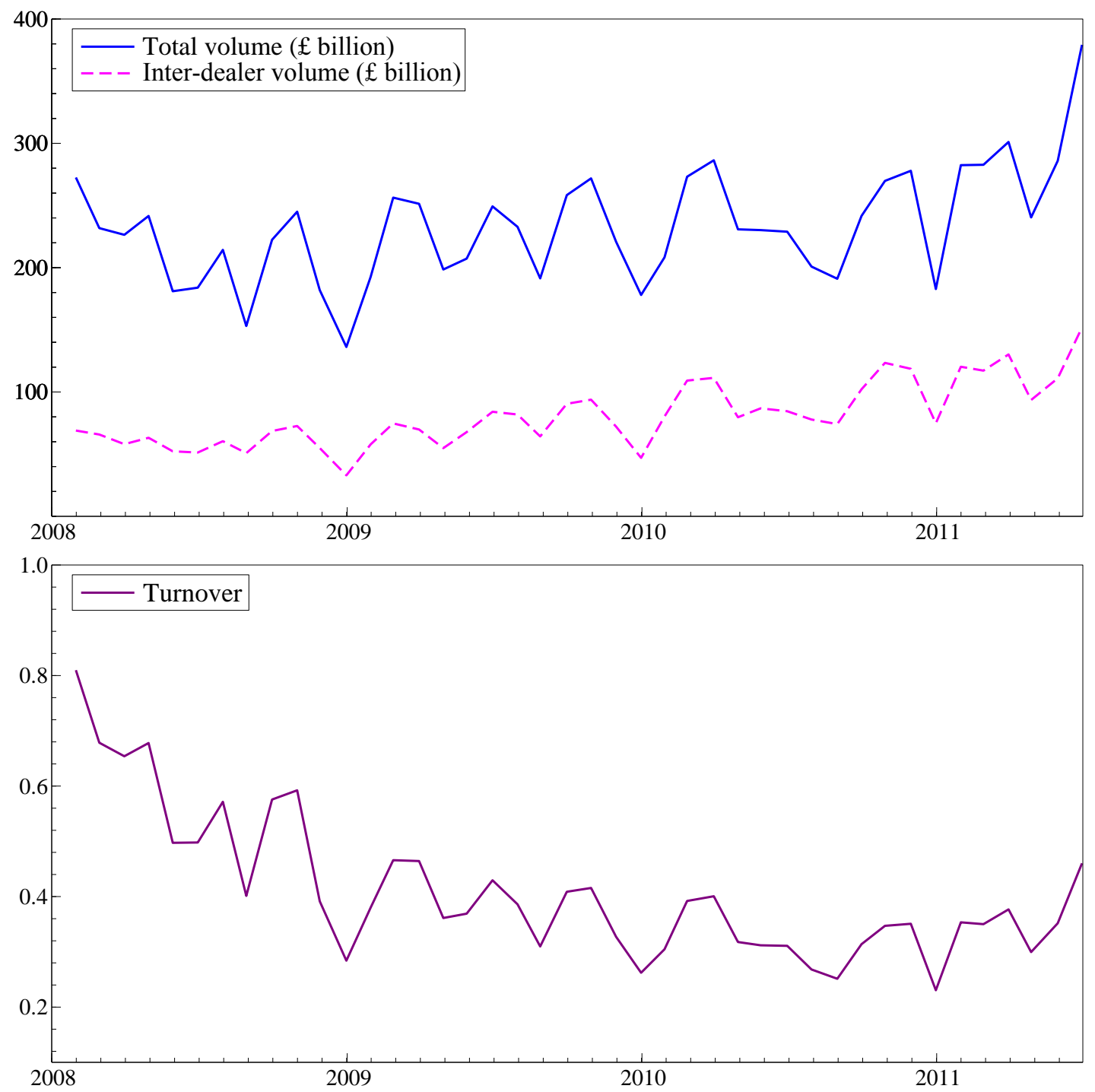
Figure 3: Aggregate liquidity, funding costs, and inventory risk.

Noise (bps, top chart), LIBOR-Repo spread (\%, middle chart) and the U.K. five-year CDS spread (bps, bottom chart). The Noise measure is defined in equation (??). The sample period is January 2, 2008 to June 30, 2011.
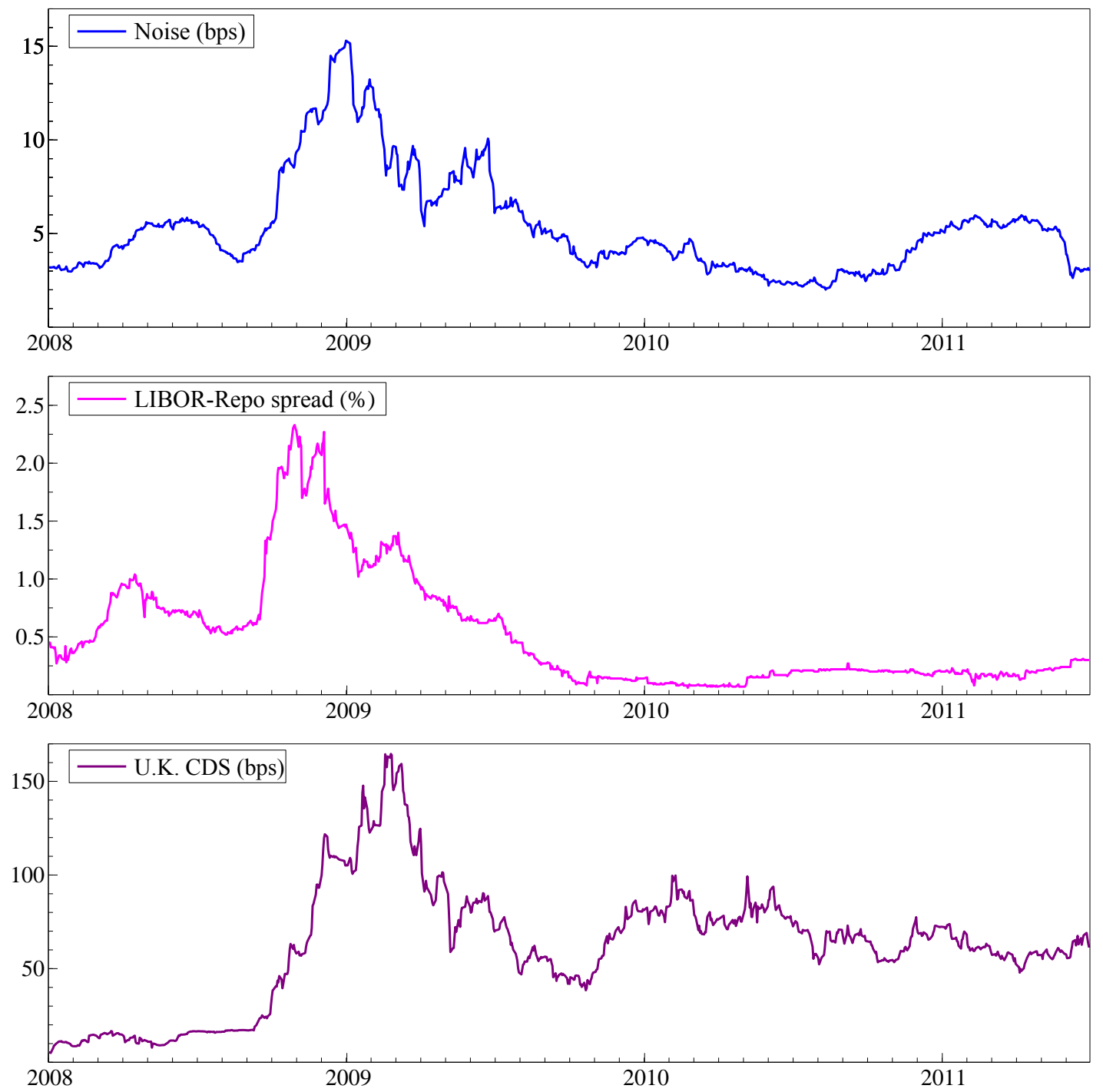
Figure 4: Bid-ask and effective spreads.

Average bid-ask and effective spreads for the gilts in our sample. The gilt-specific versions of these variables are defined in equations (??) and (??) respectively. The sample period is January 2, 2008 to June 30, 2011.
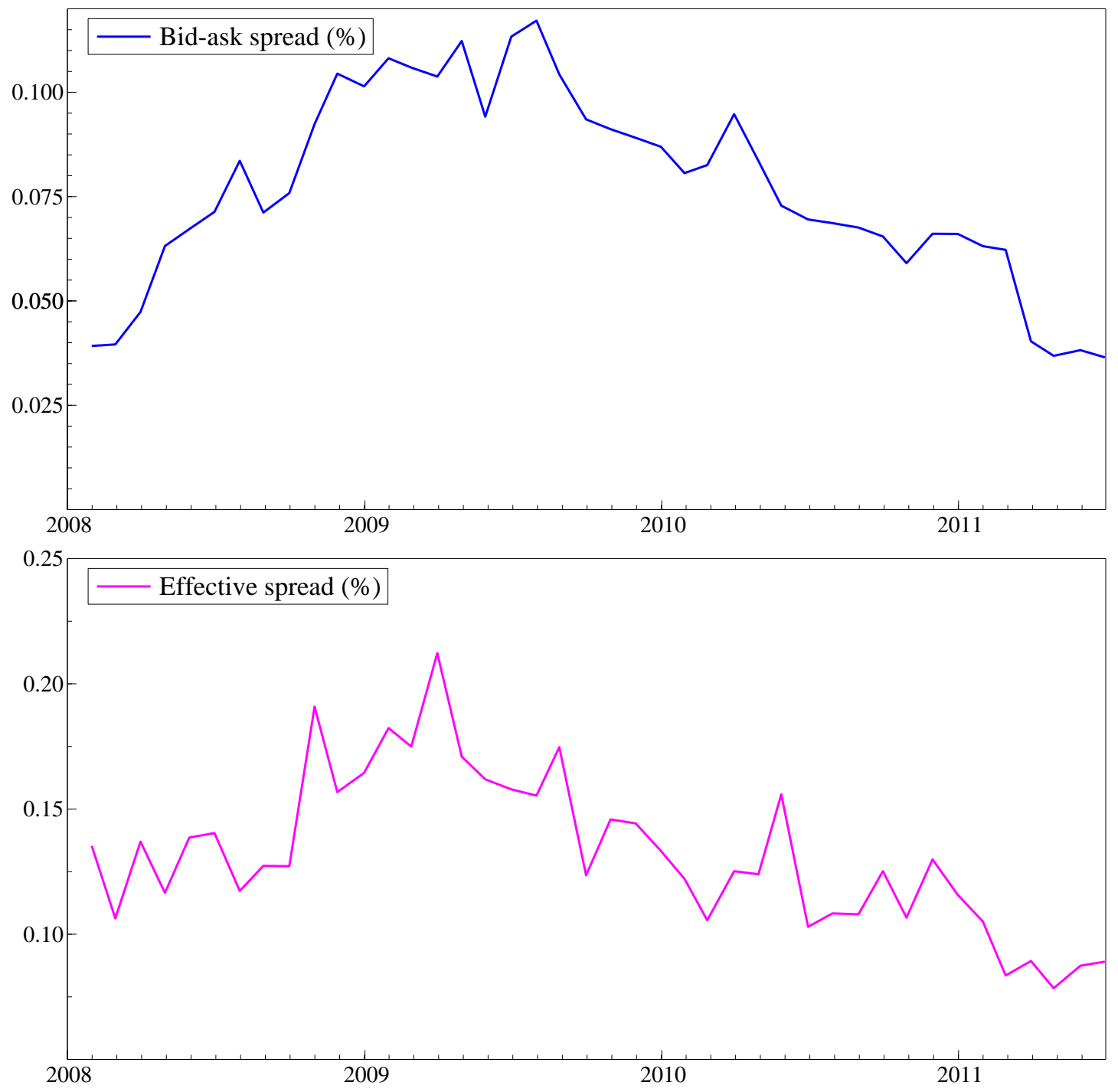